\title{
STATUS OF THE TOUGH-FLAC SIMULATOR AND RECENT APPLICATIONS RELATED TO COUPLED FLUID FLOW AND CRUSTAL DEFORMATIONS
}

\author{
Jonny Rutqvist \\ Earth Sciences Division, Lawrence Berkeley National Laboratory, MS 90-1116, \\ Berkeley, CA 947 20, USA
}

Tel.: +1-510-486-5432, fax.: +1-510-486-5686

e-mail address: jrutqvist@lbl.gov (J. Rutqvist)

June 2010 


\begin{abstract}
This paper presents recent advancement in and applications of TOUGH-FLAC, a simulator for multiphase fluid flow and geomechanics. The TOUGH-FLAC simulator links the TOUGH family multiphase fluid and heat transport codes with the commercial FLAC ${ }^{3 \mathrm{D}}$ geomechanical simulator. The most significant new TOUGH-FLAC development in the past few years is a revised architecture, enabling a more rigorous and tight coupling procedure with improved computational efficiency. The applications presented in this paper are related to modeling of crustal deformations caused by deep underground fluid movements and pressure changes as a result of both industrial activities (the In Salah $\mathrm{CO}_{2}$ Storage Project and the Geysers Geothermal Field) and natural events (the 1960s Matsushiro Earthquake Swarm). Finally, the paper provides some perspectives on the future of TOUGH-FLAC in light of its applicability to practical problems and the need for high-performance computing capabilities for field-scale problems, such as industrial-scale $\mathrm{CO}_{2}$ storage and enhanced geothermal systems. It is concluded that despite some limitations to fully adapting a commercial code such as FLAC ${ }^{3 \mathrm{D}}$ for some specialized research and computational needs, TOUGH-FLAC is likely to remain a pragmatic simulation approach, with an increasing number of users in both academia and industry.
\end{abstract}

Keywords: TOUGH, FLAC3D, modeling, fluid flow, geomechanics 


\section{INTRODUCTION}

In the 2003 TOUGH Symposium, TOUGH-FLAC which linked two established codes TOUGH2 and FLAC ${ }^{3 \mathrm{D}}$, was presented as a pragmatic approach for modeling coupled multiphase flow, heat transport, and geomechanics (Rutqvist et al., 2002; Rutqvist and Tsang, 2003a). In this approach, TOUGH2 (Pruess et al., 1999) is used for solving multiphase flow and heat transport equations, whereas FLAC $^{3 \mathrm{D}}$ (Itasca, 2009) is used for solving geomechanical stress-strain equations. The two codes are sequentially coupled and TOUGHFLAC simulation runs seamlessly on a PC. One great advantage of this approach is that both codes are continuously developed and widely used in both academia and industry.

TOUGH-FLAC is by no means the only code available for simulating coupled thermalhydraulic-mechanical processes in geological media. In fact, a steadily growing interest in coupled THM phenomena in geological media has encouraged development of many computer codes at various levels of sophistication. Among those recently applied in the field of rock mechanics are THAMES (Ohnishi and Kobayashi, 1996), MOTIF (Guvanasen and Chan, 1995), FRACON (Nguyen, 1996, Nguyen et al., 2001), ROCMAS (Noorishad et al, 1984; Rutqvist et al., 2001), FRT-THM, (Liu et al., 2006), FEMH (Bower and Zyvoloski, 1997), GeoSys/Rockflow, (Wang and Kolditz, 2007, Wang et al., 2010), , FRACture (Kohl and Hopkirk, 1995) and GEOCRACK (Swenson et al., 1997). The first five of these (THAMES, MOTIF, FRACON, ROCMAS, FRT-THM) belong to a class of simulators developed from Biot's theory of consolidation, adopting simultaneous solution of the coupled equations. They have been developed and applied mostly to geological nuclear waste disposal (e.g., Alonso et al., 2005; Chijimatsu et al., 2005). Other simulators (FEMH, GeoSys/Rockflow, FRACTure, GEOCRACK) were originally applied to the field of hot-dryrock geothermal energy, although they have also been applied to other types of coupled problems. There are also a few commercially available codes that have been applied to study these phenomena. Those most frequently applied in soil and rock mechanics are ABAQUS (Börgesson, 1996, Börgesson et al., 2001), a finite-element code; FLAC (Israelsson, 1996a), a finite-difference code; and UDEC (Israelsson, 1996b), a discrete-element code. Some of these codes have also been adapted for analysis of THM processes in unsaturated media (e.g., FRACON, FLAC, ABAQUS). At the same time, other codes have emerged from the field of soil mechanics. One of these is COMPASS (Thomas et al., 1995), which simulates two-phase (gas and liquid) fluid flow in partially saturated soil, coupled with heat transport and mechanical responses. Another code in this group is CODE-BRIGHT (Olivella et al. 1994), which originally was developed for nonisothermal multiphase flow of brine and gas in saline media.

A number of simulators have also been developed for oil and gas reservoir engineering, including commercial finite-element packages such as VISAGE (Koutsabeloulis, 1998), STARS (CMG, 2003), and a number of academic codes. Such simulators, as well as TOUGHFLAC, are in the class of coupled simulators built upon coupling of a reservoir simulator to a geomechanical code, a problem that has been studied in depth by Settari and others (e.g., Settari and Mourits, 1998). Correctly changing the porosity of the reservoir simulator upon a change in stress or strain in the mechanical code is a delicate operation; The correct poroelastic consideration is important when comparing simulation results to that of fully coupled 
poro-elastic finite element models, based on Biot's theory of the class discussed above (e.g. THAMES, MOTIF, FRACON, ROCMAS). However, as described by Settari and Mourits (1998), in practice it is more important to consider the nonlinear stress-dependent effects on porosity and permeability over the range of stress expected in a problem. Such properties may be derived directly from laboratory data and fitted to theoretical or empirical functions (e.g., Liu et al., 2009) or by calibration to field experiments (e.g., Rutqvist et al., 2008). Stability issues related to sequential coupling of geomechanics and multiphase flow has been an intensive research topic for decades (e.g., Felippa and Park, 1980; Park, 1983; Zienkiewicz et al., 1988; Lewis and Sukirman, 1993; Prevost, 1997; Minkoff et al., 2003; Thomas et al., 2003; Dean et al., 2006). Recently, an excellent and rather conclusive study was carried out by Kim (2010), showing the advantages of the sequential coupling method for this class of coupled simulators.

The earliest developments of TOUGH-FLAC at the Lawrence Berkeley National Laboratory (LBNL) were presented in Rutqvist et al. (2002) and Rutqvist and Tsang (2003a). The simulator has since been applied to study coupled geomechanical processes under multiphase flow conditions for a wide range of applications, including nuclear waste disposal (Rutqvist and Tsang, 2003b; Rutqvist et al., 2005, 2008a, 2009b, 2009c), $\mathrm{CO}_{2}$ sequestration (Rutqvist and Tsang, 2002; Rutqvist and Tsang, 2005; Tsang et al., 2008; Rutqvist et al., 2006a, 2007, 2008b, 2008c, 2010b; Cappa and Rutqvist, 2010), geothermal energy extraction (Rutqvist et al., 2006b; Rutqvist and Oldenburg, 2008), naturally occurring $\mathrm{CO}_{2}$ upwelling with surface deformations (Todesco et al., 2004; Cappa et al., 2009), and gas production from hydratebearing sediments (Rutqvist and Moridis, 2008, 2009; Rutqvist et al., 2009a).

These applications have been accompanied by recent exploratory code development. The most significant new development is a revised architecture, enabling a more rigorous and tighter coupling procedure with improved computational efficiency. This enhancement was made possible by linking FLAC ${ }^{3 \mathrm{D}}$ to the newly released TOUGH+ code (Moridis, 2003; Moridis et al., 2005) for analyzing the geomechanical performance of hydrate-bearing sediments (Rutqvist and Moridis, 2008; 2009). In addition, new modules have been developed for material behavior and modeling of hydrate-bearing sediments and the thermo-elastoplastic behavior of unsaturated soils. The development of the thermo-elastoplastic model for unsaturated soils involves implementation of a version of the Barcelona Basic Model for unsaturated soils, using the user-defined model option in FLAC ${ }^{3 \mathrm{D}}$ —described in detail in Rutqvist et al. (2010a).

This paper presents the current TOUGH-FLAC approach and some recent applications of TOUGH-FLAC. The applications presented here are related to modeling of crustal deformations caused by deep-underground fluid movements and pressure changes as a result of both industrial activities and natural events. These include (1) an analysis of groundsurface deformations measured by satellite (InSAR) at the In Salah industrial-scale $\mathrm{CO}_{2}$ injection site in Algeria and (2) at the Geysers Geothermal field in California, and (3) ground surface deformation measured by leveling during upwelling of $\mathrm{CO}_{2}$-rich fluid associated with the 1960s Matsushiro earthquake swarm in central Japan. The paper concludes with some perspectives on the future of TOUGH-FLAC in light of its applicability to practical problems and the need for high-performance computing capabilities for very large-scale problems, such 
as for the analysis of industrial-scale $\mathrm{CO}_{2}$ sequestration sites and enhanced geothermal systems.

\section{TOUGH-FLAC STRUCTURE}

The following description of the TOUGH-FLAC structure incorporates the most recent code developments, specifically linking FLAC ${ }^{3 \mathrm{D}}$ to the newly released TOUGH+ code (Rutqvist and Moridis, 2008, 2009). However, some of these ideas are concurrently being implemented for linking FLAC ${ }^{3 \mathrm{D}}$ to TOUGH2 as well. In this approach, the two constituent codesTOUGH+ (or TOUGH2) and FLAC ${ }^{3 \mathrm{D}}$ —are linked through a coupled thermal-hydrologicalmechanical (THM) model (Figure 1). Depending on the specific problem at hand and the specific porous medium (e.g., fractured rock, unsaturated clay, or hydrate-bearing sediments), a number of coupling functions have been developed.

In Figure 1, the data exchanges between TOUGH+ and FLAC ${ }^{3 \mathrm{D}}$ are illustrated with arrows going through the central THM model. The arrow on the right-hand side of Figure 1 shows the transmission of the effective stress $\sigma^{\prime}$ and strain $\varepsilon$ (computed in FLAC ${ }^{3 \mathrm{D}}$ ) to TOUGH for calculation of the updated porosity $\phi$ and the corresponding porosity change $\Delta \phi$. This mechanically induced $\Delta \phi$ has an immediate effect on fluid flow behavior. For example, if a change in $\sigma^{\prime}$ and $\varepsilon$ causes $\phi$ to decrease, the pore pressure is expected to rise, especially if the permeability is low.

For a porous deformable medium, two models for mechanically induced porosity changes are implemented in the most recent version linking FLAC $^{3 \mathrm{D}}$ to TOUGH+

(i) A poroelastic model (based on the approach proposed by Settari and Mourits, 1998) that considers macroscopic stress/strain changes and grain deformability

(ii) An empirical model (proposed by Rutqvist and Tsang, 2002) that describes a nonlinear change in porosity as a function of the effective mean stress

The $\Delta \phi$ computed from either of these models is used to estimate changes in $k$ by means of empirical equations. The updated $\phi$ and $\mathrm{k}$ values are in turn used to estimate changes in the hydraulic and wettability properties of the porous medium (i.e., aqueous- and gas-phase relative permeabilities $k_{r A}$ and $k_{r G}$, and capillary pressure $P_{c}$ ) by employing appropriate scaling equations. Currently, the capillary pressure is scaled with permeability and porosity according to a function by Leverett (1941).

For fractured media, a similar exponential empirical model has been applied to correct permeability for changes in the three-dimensional stress field (e.g., Rutqvist et al., 2002, 2008a). The fractured-media model accounts for anisotropic changes in permeability assuming three orthogonal sets of fractures such as at Yucca Mountain, Nevada (Rutqvist et al. 2008a, Rutqvist and Tsang, 2003b).

The arrow on the left side of Figure 1 depicts the flow of data obtained from TOUGH+ (or TOUGH2) (namely pressure $P$, temperature $T$, and phase saturations $S_{\beta}$ ) to FLAC ${ }^{3 \mathrm{D}}$ for processing and estimates their impact on the effective stress $\alpha \Delta P_{\beta}$ ( $\alpha$ being Biot's effective stress parameter), as well as on thermal and swelling strains ( $\varepsilon_{T}$ and $\varepsilon_{s w}$, respectively). Capabilities for modeling of moisture swelling and geomechanical behavior of unsaturated 
soil have recently been implemented into TOUGH-FLAC (see Rutqvist et al., 2010a). In this model, the swelling can either be introduced as a function of phase saturation or as a function of suction (or capillary pressure, $P_{c}$ ), using the Barcelona Basic Model for elastoplastic behavior of unsaturated soils (Rutqvist et al., 2010a).

Additionally, changes in $P, T$, and $S_{\beta}$ may also result in changes in other mechanical properties listed in Figure 1. These include bulk modulus $K$, shear modulus $G$, cohesion $C$, and coefficient of internal friction $\mu$. For example, in the case of hydrate-bearing sediment, geomechanical properties change as a function of solid-phase saturations, i.e., hydrate and ice saturations (Rutqvist and Moridis, 2009). In the case of unsaturated soil, the bulk modulus and friction angle are functions of suction (Rutqvist et al., 2010a).

In the current TOUGH-FLAC modeling approach, FLAC ${ }^{3 \mathrm{D}}$ is invoked from TOUGH+ (or TOUGH2) using a system call. This is different from the earliest version, in which TOUGH2 multiphase flow simulation was invoked from FLAC $^{3 \mathrm{D}}$. Invoking the quasistatic mechanical calculation from the multiphase flow simulation enables tighter and more rigorous coupling and improved efficiency. For example, it is now possible to invoke FLAC ${ }^{3 \mathrm{D}}$ in each Newton iteration and when calculating the Jacobian in TOUGH+. Coupling to the FLAC ${ }^{3 \mathrm{D}}$ code is still made possible through the use of the FLAC ${ }^{3 \mathrm{D}}$ FISH programming capability, which enables access to internal FLAC ${ }^{3 \mathrm{D}}$ arrays and parameters. However, the Itasca Consulting Group (which develops and maintains FLAC $^{3 \mathrm{D}}$ ) has provided new FISH variables for a more efficient transfer of TOUGH parameter directly to the FLAC $^{3 \mathrm{D}}$ grid-elements, avoiding the previous, tedious interpolation between TOUGH mid-element nodes and FLAC ${ }^{3 \mathrm{D}}$ corner nodes.

In the new TOUGH+ version, three coupling schemes are available:

(i) Jacobian: This is the highest level of iterative coupling, in which all the geomechanical and flow parameters are continuously updated (in every Newtonian iteration of every time step), and their changes are accounted for in the computation of the Jacobian matrix.

(ii) Iterative: In this scheme, the geomechanical and flow parameters are corrected at the end of each Newtonian iteration of each time step, and the contribution of their changes between Newtonian iterations is not accounted for in the computation of the Jacobian matrix.

(iii) Time-step: This represents the weakest coupling option and involves correction of the geomechanical and flow parameters once in (i.e., at the end of) each time step. As in the iterative scheme, the parameter changes do not contribute to the computation of the Jacobian matrix.

The full Jacobian option is a sequentially implicit scheme, whereas the iterative and the timestep coupling options are sequentially explicit schemes. The full Jacobian scheme is necessary for problems in which pore-volume (direct) couplings dominate, i.e., when a mechanically induced $\Delta \phi$ gives rise to a relatively strong and rapid change in pore pressure, and where it is necessary to rigorously preserve the fluid mass and heat balances. In problems when the socalled property changes (indirect) couplings dominate, iterative or time-step coupling schemes are sufficient. 
It is well known that there could be serous stability issues in problems where pore-volume coupling dominates, such as when a low permeability porous medium is mechanically squeezed by an external force. However, as it turns out, the coupling of a TOUGH and FLAC $^{3 \mathrm{D}}$ is equivalent to the coupling of a finite volume reservoir simulator to a finite element geomechanical simulator, which, according to recent work by Kim (2010), corresponds to a mixed formulation that is stable in space. Moreover, by choosing an appropriate coupling scheme with so-called stress fixed iterations in the sequential scheme, the solution becomes unconditionally stable (Kim, 2010). Work is under way to study numerical stability issues in TOUGH-FLAC when pore-volume coupling dominates. However, in the overwhelming number of multiphase flow applications encountered, the pore-volume coupling does not dominate, whereas one-way coupled, or problems in which property changes dominate, are the most common.

\section{RUNNING A TOUGH-FLAC SIMULATION}

To run a TOUGH-FLAC simulation, the user needs a license for TOUGH+ (or TOUGH2) and FLAC ${ }^{3 \mathrm{D}}$, as well as access to routines for linking the two simulators. A TOUGH-FLAC simulation is typically developed according to the steps in Figure 2. The user first develops numerical grids for the two codes that should have the same geometry and element numbering. The user then typically runs a TOUGH simulation test to make sure that the TOUGH code can execute the specific problem setup without consideration of the mechanical coupling. This may include an initially steady-state TOUGH simulation to establish initial conditions, including vertical gradients of pressure and temperature. Typical input parameters for the TOUGH simulation include grain density, porosity, permeability, thermal conductivity, specific heat, relative permeability and water retention curves, as well as hydraulic and thermal boundary conditions (e.g., fixed fluid pressure and temperature). Similarly, a FLAC ${ }^{3 \mathrm{D}}$ simulation may be conducted to assure correct input of (for example) mechanical boundary conditions and to establish initial equilibrium stress gradients. Typical input parameters for the FLAC ${ }^{3 \mathrm{D}}$ simulation include bulk density, elastic parameters (bulkand shear-modulus), strength parameters (e.g., cohesion and friction angle), as well as mechanical boundary conditions (e.g., fixed displacement or stress).

After initial runs with TOUGH and FLAC ${ }^{3 \mathrm{D}}$, the linked TOUGH-FLAC simulation is set up. This involves preparing a binary file called FLAC3D.sav that should contain the geomechanical model, as well as essential FLAC $^{3 \mathrm{D}}$ FISH routines that handle the links between $\mathrm{FLAC}^{3 \mathrm{D}}$ and $\mathrm{TOUGH}+$ (or TOUGH2). The simulation is initiated by starting a TOUGH+ (or TOUGH2) simulation with the geomechanical option activated. The first time FLAC $^{3 \mathrm{D}}$ is invoked, it restores information and the initial mechanical state from the FLAC3D.SAV binary file. FLAC ${ }^{3 \mathrm{D}}$ then reads initial pressure and temperature as defined in TOUGH+ (or TOUGH2), runs to mechanical equilibrium, and then saves the new mechanical state to the FLAC3D.SAV binary file. This procedure of restoring, running to a new mechanical equilibrium, and saving to the binary file is repeated every time the FLAC ${ }^{3 \mathrm{D}}$ mechanical calculation is invoked. The TOUGH-FLAC simulation runs seamlessly without 
need for user interference and produces required outputs for simulation times defined in the TOUGH input file.

\section{MODELING COUPLED FLUID FLOW AND CRUSTAL DEFORMATIONS}

This section summarizes recent TOUGH-FLAC simulations of crustal deformations caused by deep underground fluid movements and pressure changes as a result of both industrial activities (The In Salah $\mathrm{CO}_{2}$ storage project and the Geysers Geothermal Field) and natural events (The 1960s Matsushiro Earthquake Swarm). These simulation examples demonstrate the capabilities of TOUGH-FLAC for studying complex multiphase fluid and geomechanical processes at the crustal scale of tens of kilometers.

\subsection{In Salah Industrial $\mathrm{CO}_{2}$ Storage Project}

Since 2004, the In Salah Gas Project in Algeria has been injecting about 0.75 million tonnes $\mathrm{CO}_{2}$ per year into a relatively low-permeability, $20 \mathrm{~m}$ thick sandstone at a depth of about 1,800 to $1,900 \mathrm{~m}$ in the Krechba field (Ringrose et al., 2009). Gas produced from this field and two nearby fields contains $\mathrm{CO}_{2}$ concentrations ranging from $1 \%$ to $9 \%$, which is above the export gas specification of $0.3 \%$. The $\mathrm{CO}_{2}$ from the three fields is separated from the hydrocarbons and reinjected into three adjacent wells "KB-501, KB-502, and KB-503" at the rate of tens of millions of cubic feet per day. To ensure adequate $\mathrm{CO}_{2}$ flow-rates across the low-permeability sand-face, the In Salah Gas Project decided to use long-reach (about 1 to 1.5 $\mathrm{km}$ ) horizontal injection wells. The three state-of-the-art horizontal $\mathrm{CO}_{2}$ injection wells were drilled perpendicular to the stress field and dominant fracture orientation and targeting highporosity channel sequences to maximize the injection capacity (Ringrose et al., 2009). The $\mathrm{CO}_{2}$ injection started in August 2004 at KB501 and KB503, and April 2005 at KB502. During injection, the bottom hole pressure is limited to below the fracturing gradient, leading to a maximum pressure increase of about $10 \mathrm{MPa}$ above the ambient initial formation pressure.

In the fall of 2006, TOUGH-FLAC was used to conduct a preliminary 3D crustal scale simulation of the $\mathrm{CO}_{2}$ injection operation, which indicated that surface deformations on the orders of centimeters would be feasible (Figure 3). As a result, it was decided to explore the possibility of using the satellite-based inferrometry (InSAR) for detecting ground-surface deformations related to the $\mathrm{CO}_{2}$ injection. InSAR data were acquired and analyzed by TeleRilevamento (TRE) in Italy, using a state-of-the-art permanent scatterer method (PS), enabling determination of millimeter-scale surface deformations. The results processed in 2007 and later published in Vasco et al. (2008a,b) were remarkable, because the observed uplift could be clearly correlated with each injection well, with uplift bulges of several kilometers in diameter centered on each injection well (Figure 4). Measured uplift occurred within a month after start of the injection, with the rate of uplift $\sim 5 \mathrm{~mm}$ per year, amounting to about $1.5 \mathrm{~cm}$ in the first 3 years of injection.

In subsequent TOUGH-FLAC analysis, including measured geomechanical properties as well as actual injection flow and pressure history, Rutqvist et al. (2010b) showed that the observed uplift magnitude can be explained by pressure-induced, poro-elastic expansion of the $20 \mathrm{~m}$ 
thick injection zone. For example, Figure 5 shows a calculated uplift magnitude of $1.2 \mathrm{~cm}$ after 3 years of injection, which is similar to the measured uplift at injection well KB501. Figure 6 compares the evolution of calculated uplift with measured uplift. Again, the results shows that the observed uplift magnitude can be explained by pressure-induced, poro-elastic expansion of the $20 \mathrm{~m}$ thick injection zone. However, there could also be a significant contribution from pressure-induced deformations within a $100 \mathrm{~m}$ thick zone of shaly sands immediately above the injection zone. Moreover, analysis of a double uplift lobe pattern at the KB502 injection well indicates the strong influence of faults and fractures at reservoir depth (Vasco et al. 2010; Ringrose et al. 2009). The influence of such fault behavior is currently under investigation using TOUGH-FLAC.

The TOUGH-FLAC key input parameters for the analysis of the surface uplift are the permeability and elastic properties of the injection zone and surrounding cap rock, whereas the elastic properties of the overburden affect the result to a lesser degree. Initial estimates of the elastic properties of the injection formation were derived from laboratory experiments, whereas the properties of other geological layers were estimated using sonic logs (Rutqvist et al., 2009a). For the injection zone, a Young's modulus E $=6 \mathrm{GPa}$ and a Poisson's ratio $v=$ 0.2 were adopted from a few laboratory experiments on samples that had a porosity ranging from 15 to $20 \%$, consistent with estimates of in situ porosity. From the sonic logs, it was estimated that the cap rock (Carboniferous mudstone and tight sandstone) is somewhat stiffer and that the shallow overburden (Cretaceous sandstones and mudstones) is somewhat softer. The permeability of the injection zone was estimated to $1.3 \times 10^{-14} \mathrm{~m}^{2}$ (13 mDarcy) by model calibration, to achieve a reasonable pressure increase of about $10 \mathrm{MPa}$ (approximate value of pressure increase in the field) for an adopted injection rate of 15 MMscfd. The cap-rock permeability was varied from $1 \times 10^{-21}$ to $1 \times 10^{-19} \mathrm{~m}^{2}$, a reasonable range for shale and mudstone seals (Zhou et al., 2008).

\subsection{Geysers Geothermal Field}

The Geysers is the site of the largest geothermal electricity generating operation in the world and also one of the most seismically active regions in northern California (Majer and Peterson, 2007). It is a vapor-dominated geothermal reservoir system, hydraulically confined by low-permeability rock units. The main geologic units at The Geysers include unfractured graywacke that serves as a cap rock, metagraywacke (host to the NTR), hornfelsic graywacke (host to the HTZ), and young ( $<1 \mathrm{Ma}$ ) granitic intrusive rocks ("felsite"), which are thought to be as young as about 10,000 years before the present, and the heat source to the HTZ in the EGS demonstration area (Walters et al., 1988; Schmitt et al., 2003). As a result of the high rate of steam withdrawal, the reservoir pressure declined gradually, resulting in substantial ground subsidence. For example, leveling and GPS surveys show that from 1977 to 1996, ground subsidence occurred on the order of 0.4 to $0.8 \mathrm{~m}$ at a rate of up to $4 \mathrm{~cm}$ per year (Mossop and Segall, 1997). The subsidence occurred along with steam production from hundreds of production wells located throughout the field. In general, the subsidence is proportional to the general pressure decline in the field and could be attributed mainly to poro-elastic compaction (Mossop and Segall, 1997). Since then, the reservoir pressure has been stabilized as a result of increasing water-injection rates, using treated waste water from local communities. Water injection is necessary for economic production of steam from The 
Geysers. However, the water injection has also resulted in an increased level of seismicity, which has raised concerns regarding the social, environmental, and economic impacts on the local communities (Majer and Peterson, 2007).

The TOUGH-FLAC simulator is currently used for coupled reservoir-geomechanical analysis of The Geysers geothermal operation, in particular to study the cause and mechanisms of seismicity. As part of this study, TOUGH-FLAC was employed for studying reservoir-wide coupled geomechanical responses and surface deformation, using a generic reservoirgeomechanical simulation of a NE-SW cross-section (Figure 7 and 8). Details of model setup and results from this analysis have been presented in several papers (Rutqvist et al., 2006, Rutqvist and Oldenburg 2008). This includes derivation of appropriate rates of steam production and water injection derived from field-wide data at The Geysers from 1960 through 2005.

Archival InSAR images were acquired from approximately monthly satellite passes over the region for a seven-year period, from 1992 to 1999, and the data was analyzed by TRE on the behalf of LBNL. (After 1999, this particular satellite was out of service.). Figure 9 shows a vertical displacement profile across The Geysers along A-A in Figure 7a. The results in Figure 9 indicate a continuous settlement over the seven-year period, with a maximum settlement of $0.2 \mathrm{~m}$ at the center of the field.

Figure 10 presents a comparison of measured and calculated vertical displacements. The agreement between the measured and calculated surface deformations is surprisingly good considering the simplified generic TOUGH-FLAC model representation of The Geysers. The agreement provided a validation of the deformation model, including the choice of elastic properties, which also was supported by comparison to the previously published leveling and GPS data. The model was then used to calculate the injection-induced stress changes and their relative contribution to the cause and mechanisms of induced seismicity (Rutqvist and Oldenburg, 2008). The results of that analysis indicated that the most important cause for injection-induced seismicity at The Geysers is cooling and associated thermal-elastic shrinkage of the rock around the injected fluid, which changes the stress state in such a way that mechanical failure and seismicity can be induced. Specifically, the cooling shrinkage results in unloading and associated loss of shear strength in critically shear-stressed fractures, which are then reactivated (Rutqvist and Oldenburg, 2008).

The TOUGH-FLAC key input parameters in this case are the elastic properties and thermal expansion coefficient of the reservoir, as well as the multiphase flow properties and permeability of the reservoir and surrounding formations. The stress field is important for estimating the potential for induced seismicity, but has no effect on calculated ground-surface deformation as long as the rock behaves elastically. The equivalent fractured rock permeability in the reservoir is about $1 \cdot 10-14 \mathrm{~m} 2$ (10 millidarcies) with about $1 \%$ porosity. The includes a rock-mass bulk modulus of $3 \mathrm{GPa}$, which approximately corresponds to values back-calculated by Mossop and Segall (1997), based on strain analyses at The Geysers. The linear thermal expansion coefficient of the rock was set to $1 \times 10^{-5}{ }^{\circ} \mathrm{C}^{-1}$, corresponding to values determined on core samples of the reservoir rock at high $\left(250^{\circ} \mathrm{C}\right)$ temperature (Mossop and Segall, 1997). Using these properties, it is found that simulation results are close to observations, in particular regarding evolution of reservoir pressure, temperature, and subsidence. 


\subsection{0s Matsushiro Earthquake Swarm}

In this application example, TOUGH-FLAC was used to model coupled fluid flow and crustal deformation at the 1960s Matsushiro Earthquake Swarm in Central Japan (Ohtake, 1974, 1976). During the five-year term of the swarm, between 1965 to 1970, approximately 60,000 earthquakes were felt, and ten million tons of $\mathrm{CO}_{2}$-bearing water appeared at the ground surface, flowing up through newly created surface ruptures (Figure 11a). Ground deformations were observed with a maximum uplift of about $0.7 \mathrm{~m}$, as well as a strike slip motion along two intersecting faults (Figure 11b). One part of the research project was to use coupled multiphase flow and geomechanical modeling with TOUGH-FLAC to understand the role of a deep $\mathrm{CO}_{2}$ source on the initiation and propagation of the fault ruptures that resulted in the Matsushiro Earthquake Swarm (Cappa et al., 2009).

Figure 12 shows the three-dimensional model domain with the two intersecting faults and the deep source of $\mathrm{CO}_{2}$ rich fluid at the bottom of the model. Brine water and $\mathrm{CO}_{2}$ is injected at 6 $\mathrm{km}$ depth into a point source $\left(1 \mathrm{~km}^{2}\right)$ around the intersection of the two faults. This source represents the supply of upwelling $\mathrm{CO}_{2}$-rich brine water that may have originated from a magmatic source deeper than $10 \mathrm{~km}$ and migrated along the intersection of the two faults. The injected water contained $5 \mathrm{~g} / \mathrm{L}$ of $\mathrm{NaCl}$, and a $5 \%$ mass fraction of $\mathrm{CO}_{2}$. The fluid temperature was $190^{\circ} \mathrm{C}$. A source rate of 9,000 L/min was estimated from observed increases in surface springwater discharges (Cappa et al., 2009).

Figure 13 presents simulation results of the ground-surface uplift and evolution of surface geochemical changes. The geomechanical analysis explains the cause of the Matsushiro Earthquake Swarm as overpressure resulting from the upwelling $\mathrm{CO}_{2}$-rich fluid. Earthquake mechanisms are attributed to shear failure initiated by reduced effective stress on pre-existing fracture planes within and near the two main faults. The simulated time-dependent evolution of uplift and [Cl-] and [ $\left.\mathrm{CO}_{2}\right]$ concentration shown in Figure 13 is consistent with field observations of spring outflows at Matsushiro (Cappa et al., 2009; Yoshida et al., 2003). Interestingly, both simulations and field observations show that surface deformation and increased seismicity were precursors to the $\mathrm{CO}_{2}$ surface release, since the mechanical responses were detected up to a year before any chemical changes were measured at the ground surface.

The TOUGH-FLAC key input parameters in this case were, again, permeability and elastic properties, and the initial stress field. These parameters were calibrated and constrained by various observations and geophysical measurements. The values of Young's modulus for a deeper high-velociity zone and a shallower (0 to $1500 \mathrm{~m}$ depth) low velocity zone of the host rock were set to about 7 and 15 GPa, respectively, which were about $60 \%$ of the dynamic properties estimated from sonic velocity profiles. The permeability of the fault zone was set to $1 \times 10^{-16} \mathrm{~m}^{2}$ based on estimates from a fault injection experiment conducted at the site in the 1970s (Othtake, 1974). Based on observations at the fault experiment, and based on other studies of hydromechanical behavior for fractured rocks (Min et al., 2004; Rutqvist and Stephansson, 2003), the maximum permeability increase upon fault reactivation was set to about 2 orders of magnitude. The simulation results also indicated that field observations could not be matched without considering fault permeability changes with reactivation. 
Finally, at the intersection of the two faults, we applied a higher initial permeability (ko $=5 \times$ $10^{-15} \mathrm{~m} 2$ ), necessary for matching $\mathrm{Cl}$ evolution at the ground surface as well as matching the extent of the uplift bulge centered around the fault intersection.

\section{DISCUSSION AND CONCLUDING REMARKS}

Over the past 8 years, TOUGH-FLAC has been successfully applied to a wide range of problems related to coupled multiphase fluid flow and geomechanical processes in geological media. In this paper, three application examples were presented that demonstrate the applicability of TOUGH-FLAC to very-large-scale problems, including industrial-scale $\mathrm{CO}_{2}$ injection and geothermal energy extraction operations, as well as crustal-scale geological processes. These application examples were selected because they are recent, related to a common theme, and demonstrate the practical applicability of the TOUGH-FLAC approach to field-scale problems. This is important, because the capabilities of a numerical simulator can usually be best judged by the number and types of applications that have been published in the open literature.

One of the advantages of TOUGH-FLAC is that both the TOUGH family codes and FLAC ${ }^{3 \mathrm{D}}$ are already established and are continuously developed within their respective fields, and therefore model developments can be focused on the coupling of the two codes. The simulator is not a completely closed black-box commercial package, but rather one that provides considerable flexibility for a wide range of applications. Another great advantage is that using TOUGH-FLAC promotes multidisciplinary collaboration among hydrologists (who may be familiar with TOUGH) and geomechanists (who may be familiar with FLAC ${ }^{3 \mathrm{D}}$ ) to solve complex coupled problems that might be difficult to grasp for one person within one particular field. One good example is the application of TOUGH-FLAC to analyzing the geomechanical performance of gas hydrates.

In parallel with the development and application of TOUGH-FLAC, several research groups have been working with similar or alternative approaches for considering geomechanical coupling in the TOUGH family codes. This includes, but is likely not limited to, Gosavi and Swenson (2005), Javeri (2007), Hurwitz et al. (2007) and Taron et al. (2009). Gosavi and Swenson (2005) linked TOUGH2 to the finite element code GeoCrack3D for a more tightly coupled code, and later applied it to geothermal energy applications. Javeri (2007) linked TOUGH2 and FLAC ${ }^{3 \mathrm{D}}$ in a similar manner to Rutqvist et al. (2002) and applied it to study geomechanical effects of gas generation and pressure buildup in a nuclear waste repository. Hurwitz et al. (2007) linked TOUGH2 to the coupled hydromechanical finite element code Biot2 and applied it to study hydrothermal fluid flow and deformation in large calderas, inspired by earlier TOUGH-FLAC modeling of similar phenomena reported in Todesco et al. (2004). Finally, Taron et al. (2009) applied coupled TOUGHREACT and FLAC ${ }^{3 \mathrm{D}}$ using a stationary CM coupling relationship for rock fractures (Min et al., 2009) to study coupled THMC phenomena for hot-dry-rock geothermal extraction applications. 
Despite the success in applying TOUGH-FLAC to a wide range of geoscience and engineering problems, one drawback with the current TOUGH-FLAC simulator is that it runs exclusively on a Windows platform (because FLAC ${ }^{3 \mathrm{D}}$ runs on Windows exclusively), which prevents us from applying the approach on existing Unix clusters for massive parallel processing. Therefore, other options for capturing geomechanics in the TOUGH family codes, including using geomechanical research codes with full access to the source code, will be explored in the near future. This work will also include coupling to TOUGHREACT and may be conducted within the framework of future TOUGH+ developments. Moreover, future work will put more emphasis on improving algorithms for direct, pore-volume coupling caused by poro-elastic and thermal stress under various permeability ranges. However, because FLAC ${ }^{3 D}$ is a commercial code that is continuously improved and maintained for practical applications, TOUGH-FLAC is likely to remain as a gereral, pragmatic approach with increased number of users, especially for applications requiring advanced multiphase flow analysis linked with the geomechanics of complex, highly nonlinear and/or time-dependent constitutive behavior.

\section{ACKNOWLEDGMENTS}

This paper was completed with funding from the Assistant Secretary for Fossil Energy, Office of Natural Gas and Petroleum Technology, through the National Energy Technology Laboratory, and Assistant Secretary for Energy Efficiency and Renewable Energy, Geothermal Technologies Program, of the U.S. Department under the U.S. Department of Energy Contract No. DE-AC02-05CH11231. Technical review by Hui-Hai Liu and editorial review by Dan Hawkes at LBNL are greatly appreciated. I would like to thank my collaborators (most of them co-authors in cited papers) for their contributions to the development and application of TOUGH-FLAC, especially George Moridis and Yu-Shu Wu at LBNL, as well as Edward Dzik and Christine Detournay at ITASCA, Minneapolis. I would also like to thank Chin-Fu Tsang at LBNL for his initial encouragement and promotion of TOUGH-FLAC, an approach that has been much more useful than I initially thought.

\section{REFERENCES}

Alonso, E.E., Alcoverro, J., et al., (26 co-authors), 2005. The FEBEX Bechmark test. Case Definition and comparison of modelling approaches. International Journal of Rock Mechanics and Mining Sciences 42, 611-638.

Bower, K.M., Zyvoloski, G., 1997. A numerical model for thermo-hydro-mechanical coupling in fractured rock. International Journal of Rock Mechanics and Mining Sciences 34, 1201-1211.

Börgesson, L., 1996. ABAQUS, In: Stephansson, O., Jing, L., Tsang, C.-F. (Eds.), Coupled Thermo-Hydro-Mechanical Processes of Fractured Media, Developments in Geotechnical Engineering, Elsevier, 79, pp. 565-570.

Börgesson, L., Chijimatsu, M., Nguyen, T.S., Rutqvist, J., Jing, L., 2001. Thermo-hydromechanical characterization of a bentonite-based buffer material by laboratory tests and numerical back analyses. International Journal of Rock Mechanics and Mining Sciences 38, 105-127. 
Cappa, F., Rutqvist, J., 2010. Modeling of coupled deformation and permeability evolution during fault reactivation induced by deep underground injection of CO2. International Journal of Greenhouse Gas Control (Accepted).

Cappa, F., Rutqvist, J., Yamamoto, K., 2009. Modeling crustal deformation and rupture processes related to upwelling of deep $\mathrm{CO}_{2}$ rich fluids during the 1965-1967 Matsushiro Earthquake Swarm in Japan. Journal of Geophysical Research 114: B10304, doi:10.1029/2009JB006398.

Chijimatsu, M., Nguyen, T.S., Jing, L., De Jonge, J., Kohlmeier, M., Millard, A., Rejeb, A., Rutqvist, J., Souley, M., Sugita, Y., 2005. Numerical study of the THM effects on the near-field safety of a hypothetical nuclear waste repository - BMT1 of the DECOVALEX III project. Part 1: Conceptualization and characterization of the problems and summary of results. International Journal of Rock Mechanics and Mining Sciences 42, 720-730.

CMG, 2003. User's Guide STARS. Computer Modelling Group Ltd., Calgary, Canada.

Dean, R.H., Gai, S., Stone, C.M., Minkoff, S.E., 2006. A comparison of techniques for coupling porous flow and geomechanics. Society of Petroleum Engineers Journal 11, $132-140$.

Felippa, C.A., Park, K.C., 1980. Staggered transient analysis procedures for coupled mechanical systems: formulation. Computational Methods and Applied Mechanical Engineering 24, 61-111.

Gosavi, S., Swenson, D., 2005. Architecture for a coupled code for multiphase fluid flow, heat transfer and deformation in porous rock. In: Proceedings of the Thirtieth Workshop on Geothermal Reservoir Engineering Stanford University, Stanford, California, January 31-February 2, 2005.

Guvanasen, V., Chan, T., 1995. A new three-dimensional finite-element analysis of hysteresis thermohydromechanical deformation of fractured rock mass with dilatance in fractures. In: Proceedings of the 2nd Conference on Mechanics of Jointed and Faulted Rocks, Vienna, Austria, April 10-14, pp. 347-442.

Hurwitz, S., Christiansen, L.B., Hsieh, P.A., 2007. Hydrothermal fluid flow and deformation in large calderas: Inferences from numerical simulations. Journal of Geophysical Research, 112, BO2206.

Israelsson, J.I., 1996. Short description of FLAC version 3.2. In: Stephansson, O., Jing, L., Tsang, C.-F. (Eds.), Coupled Thermo-hydro-mechanical Processes of Fractured Media. Developments in Geotechnical Engineering, Elsevier, 79, pp. 513-522.

Israelsson, J.I., 1996. Short description of UDEC and 3DEC. In: Stephansson, O., Jing, L., Tsang, C.-F. (Eds.), Coupled Thermo-hydro-mechanical Processes of Fractured Media. Developments in Geotechnical Engineering, Elsevier, 79, pp. 523-528.

Itasca, 2009. FLAC ${ }^{3 \mathrm{D}}$, Fast Lagrangian Analysis of Continua in 3 Dimensions, Version 4.0. Minneapolis, Minnesota, Itasca Consulting Group, 438pp.

Javeri, V., 2007. Three dimensional analysis of combined gas, heat and nuclide transport in a repository in clay rock including coupled thermo-hydro-geomechanical processes. Physics and Chemistry of the Earth, 33, S252-S259.

Kim, J., 2010. Sequential methods for coupled geomechanics and multiphase flow. Ph.D. Thesis, Department of Energy Resources Engineering, Stanford University, California, 264 pp. 
Kohl, T., Hopkirk, R.J., 1995. The finite element program "FRACTure” for the simulation of Hot Dry Rock reservoir behavior. Geothermics 24, 345-359.

Koutsabeloulis, N.C., Hope, S.A., 1998. Coupled stress/fluid/thermal multi-phase reservoir simulation studies incorporating rock mechanics. In: Proceedings of SPE/ISRM EUROCK-98 symposium, Norway, 449-454.

Leverett, M.C., 1941. Capillary behavior in porous media. Trans, AIME, 142, 341-358.

Lewis, R.W., Sukirman, Y., 1993. Finite element modelling of three-phase flow in deforming saturated oil reservoirs. International Journal of Numerical and Analytical Methods in Geomechanics 17, 577-598.

Liu, H.H., Rutqvist, J., Berryman, J.C., 2009. On the relationship between stress and elastic strain for porous and fractured rock. International Journal of Rock Mechanics and Mining Sciences 46, 289-296.

Liu, Q., Zhang, C., Liu, X., 2006. A practical method for coupled THM simulations of the Yucca Mountain and FEBEX case samples for task D of the DECOVALEX-THMC Project. In: Proceedings of GEOPROC2006 International symposium: 2nd International Conference on Coupled Thermo-hydro-mechanical-chemical processes in Geosystems and Engineering, HoHai University, Nanjing, China, May 22-25, 2006, p. 220-225.

Majer, E.L., Peterson, J.E., 2007. The impact of injection on seismicity at The Geysers, California Geothermal Field. Geothermics 44, 1079-1090.

Min, K.-B., Rutqvist, J., Elsworth, D., 2009. Chemically and mechanically mediated influences on the transport and mechanical characteristics of rock fractures. International Journal of Rock Mechanics and Mining Sciences 46, 80-89.

Min, K.-B., Rutqvist, J., Tsang, C.-F., Jing., L., 2004. Stress-dependent permeability of fracture rock masses: a numerical study. International Journal of Rock Mechanics and Mining Sciences 41, 1191-1210.

Minkoff, S.E., Stone, C.M., Bryant, S., Peszynska, M., Wheeler, M.F., 2003. Coupled fluid flow and geomechanical deformation modeling. Journal of Petroleum Sciences and Engineering 38, 37-56.

Moridis, G.J., 2003. Numerical Studies of Gas Production From Methane Hydrates. Society of Petroleum Engineers (SPE) Journal 32, 359-370.

Moridis, G.J., Kowalsky, M., Pruess, K., 2005. TOUGH-Fx/HYDRATE v1.0 User’s Manual: A code for the Simulation of System Behavior in Hydrate-Bearing Geologic Media. Lawrence Berkeley National Laboratory, Berkeley, California, USA. 246pp.

Mossop, A.P., Segall, P., 1997. Subsidence at The Geysers geothermal field, N. California from a comparison of GPS and leveling surveys, Geophysical Research Letters, 24, $1839-1842$.

Nguyen, T.S., 1996. Description of the computer code FRACON. In: Stephansson, O., Jing, L., Tsang, C.-F. (Eds.), Coupled Thermo-Hydro-Mechanical Processes of Fractured Media. Developments in Geotechnical Engineering, Elsevier, 79, pp. 539-544.

Nguyen, T.S., Börgesson, L., Chijimatsu, M., Rutqvist, J., Fujita, T., Hernelin, J., Kobayashi, A., Onishi, Y., Tanaka, M., Jing, L., 2001. Hydro-mechanical response of a fractured rock mass to excavation of a test pit - The Kamaishi Mine Experiment in Japan. International Journal of Rock Mechanics and Mining Sciences 38, 79-94.

Noorishad, J., Tsang, C.-F., Witherspoon, P.A., 1984. Coupled thermal-hydraulic-mechanical phenomena in saturated fractured porous rocks: numerical approach. Journal of Geophysical Research 89, 10365-10373. 
Ohnishi, Y., Kobayashi, A., 1996. THAMES. In: Stephansson, O., Jing, L., Tsang, C.-F. (Eds.), Coupled Thermo-Hydro-Mechanical Processes of Fractured Media. Developments in Geotechnical Engineering, Elsevier, 1996, 79, pp. 545-549.

Ohtake, M., 1974. Seismic activity induced by water injection at Matsushiro, Japan. Journal of the Physics of the Earth 22, 163-176.

Ohtake, M., 1976. A review of the Matsushiro earthquake swarm. Kagaku 46, 306-313 [in Japanese].

Olivella, S., Carrera, J., Gens, A., Alonso, E.E., 1994. Nonisothermal multiphase flow of brine and gas through saline media. Transport in Porous Media 15, 271-293.

Park, K.C., 1983. Stabilization of partitioned solution procedure for pore fluid-soil interaction analysis. International Journal of Numerical Methods in Engineering 19, 1669-1673.

Prevost, J.H., 1997. Partitioned solution procedure for simultaneous integration of coupledfield problems. Communications in Numerical Methods in Engineering 13, 239-247.

Pruess, K., García, J., Kovscek, J.T., Oldenburg, C., Rutqvist, J., Steefel, C., Xu, T., 2004. Code intercomparison builds confidence in numerical simulation models for geologic disposal of $\mathrm{CO}_{2}$. Energy 29, 1431-1444.

Pruess, K., Oldenburg, C., Moridis, G., 1999. TOUGH2 User’s Guide, Version 2.0, Report LBNL-43134, Lawrence Berkeley National Laboratory, Berkeley, California, 198pp.

Ringrose, P., Atbi, M., Mason, D., Espinassous, M., Myhrer, Ø., Iding, M., Mathieson, A., Wright, I., 2009. Plume development around well KB-502 at the In Salah CO2 storage site. First Break 27, 85-89.

Rutqvist, J., Barr, D., Birkholzer, J.T., Chijimatsu, M., Kolditz, O., Liu, Q., Oda, Y., Wang, W., Zhang, C., 2008c. Results from an international simulation study on coupled thermal, hydrological, and mechanical (THM) processes near geological nuclear waste repositories. Nuclear Technology 163, 101-109.

Rutqvist, J., Barr, D., Birkholzer, J.T., Fujisaki, K., Kolditz, O., Liu, Q.-S., Fujita, T., Wang, W., Zhang, C.-Y., 2009b. A comparative simulation study of coupled THM processes and their effect on fractured rock permeability around nuclear waste repositories. Environmental Geology 57, 1347-1360.

Rutqvist, J., Barr, D., Datta, R., Gens, A., Millard, A., Olivella, S., Tsang, C.-F., Tsang, Y., 2005. Coupled thermal-hydrological-mechanical analysis of the Yucca Mountain Drift Scale Test - comparison of field results to predictions of four different models. International Journal of Rock Mechanics and Mining Sciences 42, 680-697.

Rutqvist, J., Birkholzer, J.T., Cappa, F., Oldenburg, C., Tsang, C.-F., 2006b. Shear-slip analysis in multiphase fluid-flow reservoir engineering applications using TOUGHFLAC. In: Proceedings of the TOUGH symposium 2006, Lawrence Berkeley National Laboratory, Berkeley, California, May 15-17.

Rutqvist, J., Birkholzer, J., Cappa, F., Tsang, C.-F., 2007. Estimating maximum sustainable injection pressure during geological sequestration of $\mathrm{CO}_{2}$ using coupled fluid flow and geomechanical fault-slip analysis. Energy Conversion and Management 48, 1798-1807.

Rutqvist, J., Birkholzer, J.T., Tsang, C.-F., 2006a. Modeling hydrological and geomechanical processes related to $\mathrm{CO}_{2}$ injection in a faulted multilayer system. In: Proceedings of the 8th International Conference on Greenhouse Gas Control Technologies, Trondheim, Norway, June 19-22.

Rutqvist, J., Birkholzer, J.T., Tsang, C.-F., 2008b. Coupled reservoir-geomechanical analysis of the potential for tensile and shear failure associated with $\mathrm{CO}_{2}$ injection in multilayered 
reservoir-caprock systems. International Journal of Rock Mechanics and Mining Sciences 45, 132-143.

Rutqvist, J., Bäckström, A., Chijimatsu, M., Feng, X-T, Pan, P-Z., Hudson, J, Jing, L., Kobayashi, A., Koyama, T., Lee, H.-S., Huang, X.-H., Rinne, M., Shen, B., 2009c. Multiple-code simulation study of the long-term EDZ evolution of geological nuclear waste repositories. Environmental Geology 57, 1313-1324.

Rutqvist J., Börgesson, L., Chijimatsu, M., Kobayashi, A., Nguyen, T. S., Jing, L., Noorishad J., Tsang, C.-F., 2001. Thermohydromechanics of Partially Saturated Geological Media Governing Equations and Formulation of Four Finite Element Models. International Journal of Rock Mechanics and Mining Sciences 38, 105-127.

Rutqvist, J., Freifeld, B., Min, K.-B., Elsworth, D., Tsang, Y., 2008a. Analysis of thermally induced changes in fractured rock permeability during eight years of heating and cooling at the Yucca Mountain Drift Scale Test. International Journal of Rock Mechanics and Mining Sciences 45, 1373-1389.

Rutqvist, J., Ijiri, Y., Yamamoto, H., 2010a. Implementing the Barcelona Basic Model into TOUGH-FLAC for analysis of geomechanical behavior of unsaturated soils. (Submitted).

Rutqvist, J., Moridis, G.J., 2009. Numerical Studies on the Geomechanical Stability of Hydrate-Bearing Sediments. Society of Petroleum Engineers (SPE) Journal 14, 267-282, SPE-126129.

Rutqvist, J., Moridis, G., 2008. Development of a Numerical Simulator for Analyzing the Geomechanical Performance of Hydrate-Bearing Sediments. In: Proceedings of the $42^{\text {nd }}$ U.S. Rock Mechanics Symposium, San Francisco, California, USA, June 29-July 2, 2008, American Rock Mechanics Association, ARMA, Paper No. 139.

Rutqvist, J., Moridis, G.J., Grover, T., Collett, T., 2009a. Geomechanical response of permafrost-associated hydrate deposits to depressurization-induced gas production. Journal of Petroleum Science and Engineering 67, 1-12.

Rutqvist, J., Oldenburg, C.M., 2008. Analysis of injection-induced micro-earthquakes in a geothermal steam reservoir, Geysers Geothermal Field, California. In: Proceedings of the 42th U.S. Rock Mechanics Symposium, San Francisco, California, USA, June 29-July 2, 2008, American Rock Mechanics Association ARMA, Paper No. 151.

Rutqvist, J., Stephansson, O., 2003. The role of hydromechanical coupling in fractured rock engineering. Hydrogeology Journal 11, 7-40.

Rutqvist, J., Tsang, C.-F., 2005. Coupled hydromechanical effects of $\mathrm{CO}_{2}$ injection. In: Tsang C.F., Apps J.A., (Eds.), Underground Injection Science and Technology. Elsevier, pp. 649-679.

Rutqvist, J., Tsang, C.-F., 2003a. TOUGH-FLAC: A numerical simulator for analysis of coupled thermal-hydrologic-mechanical processes in fractured and porous geological media under multi-phase flow conditions. In: Proceedings of the TOUGH symposium 2003, Lawrence Berkeley National Laboratory, Berkeley, May 12-14, 2003.

Rutqvist, J., Tsang, C.-F., 2003b. Analysis of thermal-hydrologic-mechanical behavior near an emplacement drift at Yucca Mountain. Journal of Contaminant Hydrology 62-63, 637-652.

Rutqvist, J., Tsang, C.-F., 2002. A study of caprock hydromechanical changes associated with $\mathrm{CO}_{2}$ injection into a brine aquifer. Environmental Geology 42, 296-305. 
Rutqvist, J., Vasco, D., Myer, L., 2010b. Coupled reservoir-geomechanical analysis of $\mathrm{CO}_{2}$ injection at In Salah, Algeria. International Journal of Greenhouse Gas Control 4, 225230.

Rutqvist, J., Wu, Y.-S., Tsang, C.-F., Bodvarsson, G., 2002. A modeling approach for analysis of coupled multiphase fluid flow, heat transfer, and deformation in fractured porous rock. International Journal of Rock Mechanics and Mining Sciences 39, 429-442.

Schmitt, A.K., Grove, M., Harrison, T.M., Lovera, O., Hulen, J., Walters, M., 2003. The Geysers - Cobb Mountain Magma System, California (Part 2): timescales of pluton emplacement and implications for its thermal history. Geochimica et Cosmochimica Acta 67, 3443-3458.

Settari, A., Mourits, F.M., 1998. A Coupled reservoir and Geomechanical Simulation System. Society of Petroleum Engineers (SPE) Journal 27(9), 219-226, SPE paper 50939.

Swenson, D.V., DuTeau, R., Sprecker, T., 1997. A coupled model of fluid flow in jointed rock applied to simulation of a hot dry rock reservoir. International Journal of Rock Mechanics and Mining Sciences 34, Paper 308.

Taron, J., Elsworth, D., Min, K.-B., 2009. Numerical simulation of thermal-hydrologicmechanical-chemical processes in deformable, fractured porous media. International Journal of Rock Mechanics and Mining Sciences 46, 842-854.

Thomas, H.R., Sansom, M.B., 1995. Fully coupled analaysis of heat, moisture, and air transfer in unsaturated soil. Journal of Engineering Mechanics ASCE 121, 392-405.

Thomas, L.K., Chin, L.Y., Pierson, R.G., Sylte, J.E., 2003. Coupled geomechanics and reservoir simulation. Society of Petroleum Engineers (SPE) Journal 8, 350-358.

Todesco, M., Rutqvist, J., Chiodini, G., Pruess, K., Oldenburg, C.M., 2004. Modeling of recent volcanic episodes at Phlegrean Fields (Italy): geochemical variations and ground deformation. Geothermics 33, 531-547.

Tsang, C.-F., Birkholzer, J., Rutqvist, J., 2008. A Comparative Review of Hydrologic Issues Involved in Geologic Storage of CO2 and Injection Disposal of Liquid Waste. Journal of Environmental Geology 54, 1723-1737.

Vasco, D.W., Ferretti, A., Novali, F., 2008a. Estimating permeability from quasi-static deformation: Temporal variations and arrival time inversion. Geophysics 73, O37-O52.

Vasco, D.W., Ferretti, A., Novali, F., 2008b. Reservoir monitoring and characterization using satellite geodetic data: Interferometric Synthetic Aperture Radar observations from the Krechba field, Algeria. Geophysics 73, WA113-WA122.

Vasco, D.W., Rucci, A., Ferretti, A., Novali, F., Bissell, R.C., Ringrose, P.S., Mathieson, A.S., Wright, I.W., 2010. Satellite-based measurements of surface deformation reveal fluid flow associated with the geological storage of carbon dioxide. Geophysical Research Letters 37, 3, doi:10.1029/2009GL041544.

Walters, M.A., Sternfeld, J.N, Haizlip, J.R., Drenick, A.F., Combs, J., 1988. A vapordominated reservoir exceeding $600^{\circ} \mathrm{F}$ at The Geysers Sonoma County, California. In: Proceedings, 13th Workshop on Geothermal Reservoir Engineering, Stanford University, SGP-TR-113, 73-81.

Wang, W., Kolditz, O., 2007. Object-oriented finite element analysis of thermo-hydromechanical (THM) problems in porous media. International Journal Numerical Methods Engineering 69, 162-201. 
Wang, W., Rutqvist, J., Görke, U.-J., Birkholzer, J.T., Kolditz, O., 2010. Non isothermal flow in low permeable porous media: A comparison of Richards' and two-phase flow approaches. Environmental Earth Sciences (in press).

Yoshida, N., H. Tsukahara, T., Okusawa, 2003. Andesitic magmatic water which generated Matsushiro earthquake swarm and S wave reflector, AGU Fall Meeting, V52B-0437.

Zhou, Q., Birkholzer, J.T., Tsang, C.-F., Rutqvist, J., 2008. A method for quick assessment of $\mathrm{CO} 2$ storage capacity in closed and semi-closed saline formations. International Journal of Greenhouse Gas Control 2, 626-639.

Zienkiewicz, O.C., Paul, D.K., Chan, A.H.C., 1988. Unconditionally stable staggered solution procedure for soil-pore fluid interaction problems. International Journal of Numerical Methods Engineering 26, 1039-1055. 


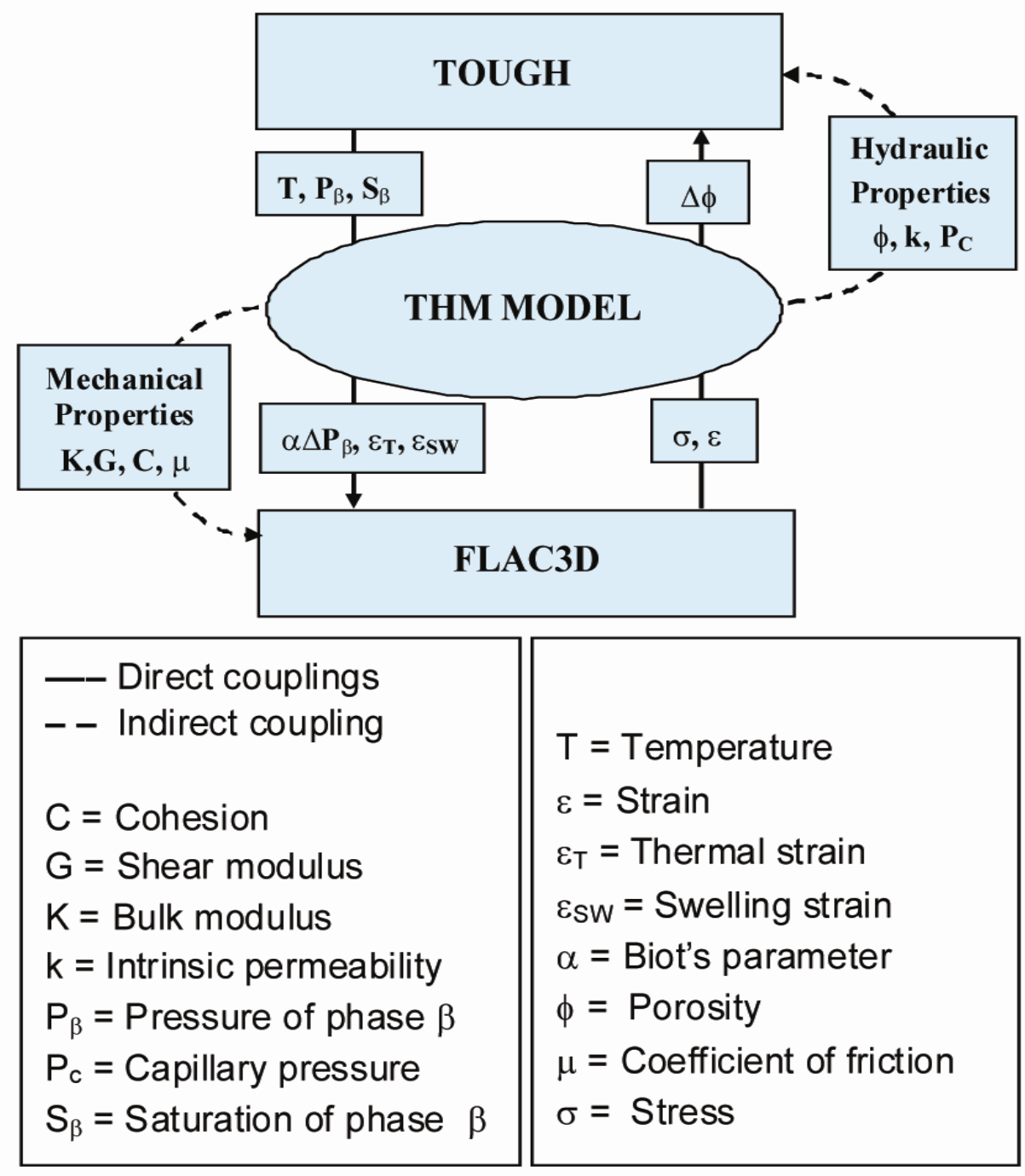

Figure 1. Schematic of linking TOUGH family code such as TOUGH+ and TOUGH2 with FLAC $^{3 \mathrm{D}}$ for a coupled THM simulation. 


\section{TOUGH}

Make a mesh using Meshmaker or external mesh generator

$\checkmark$

Prepare TOUGH input data file (properties, boundary, and initial conditions)
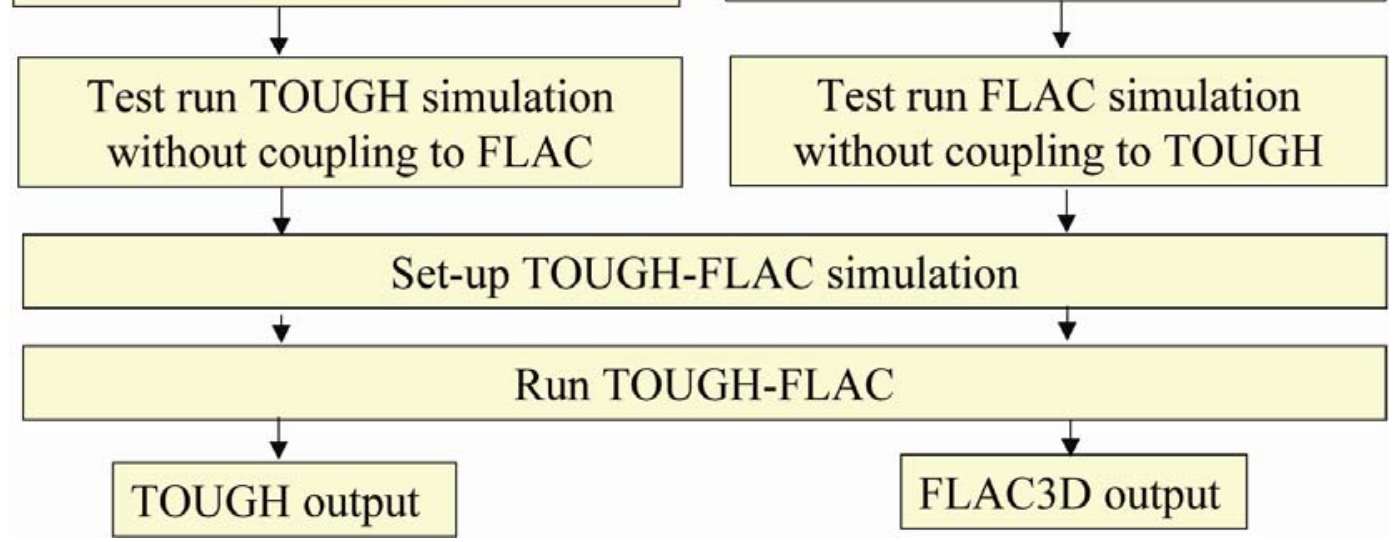

Figure 2. Steps for developing a coupled TOUGH-FLAC simulation of a particular problem. 


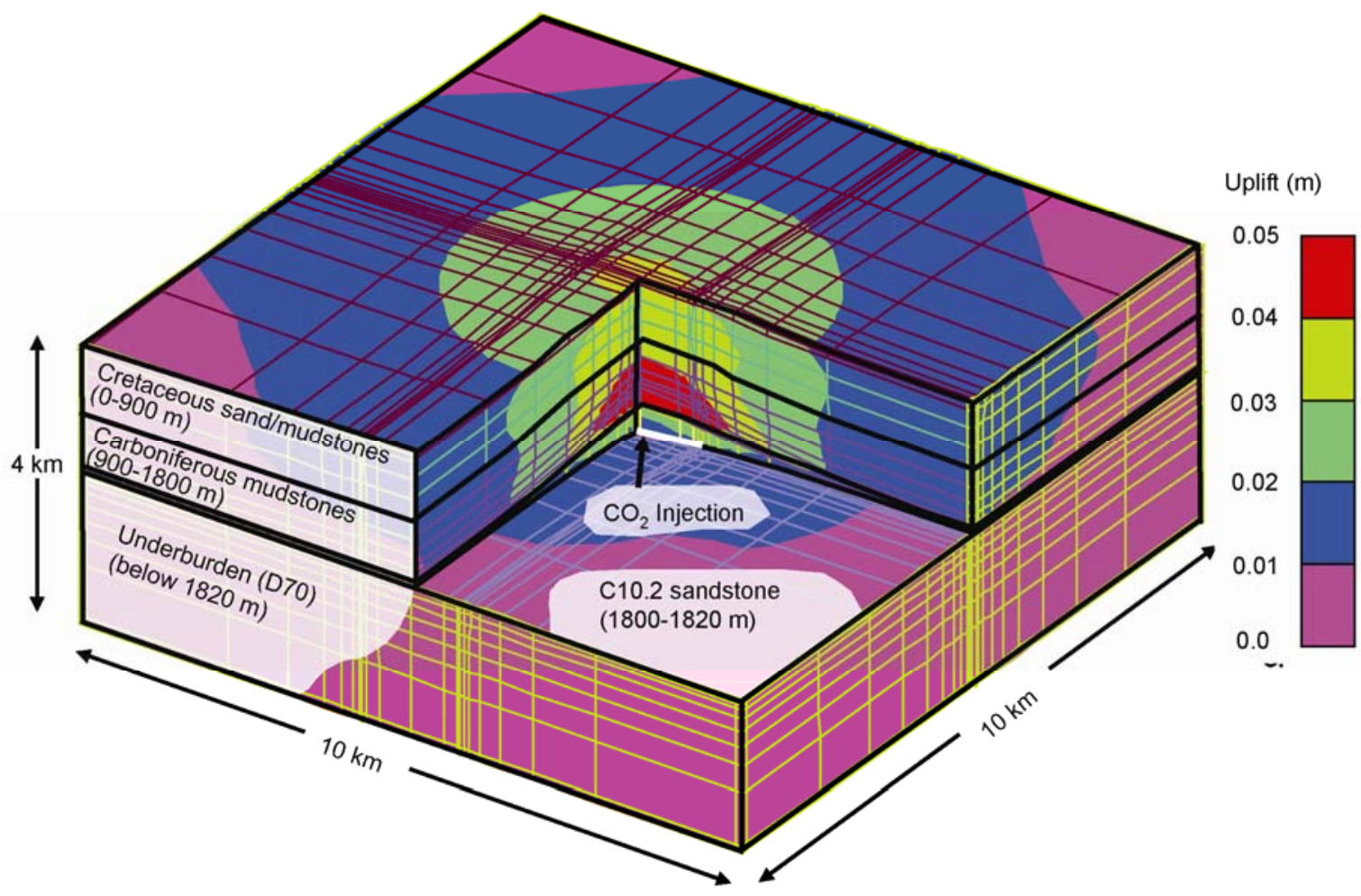

Figure 3. Model geometry for TOUGH-FLAC coupled reservoir-geomechanical analysis of $\mathrm{CO}_{2}$ injection and ground surface deformations at Krechba with preliminary simulation results of uplift from 2006. Model is centered on one $\mathrm{CO}_{2}$ injection well. 


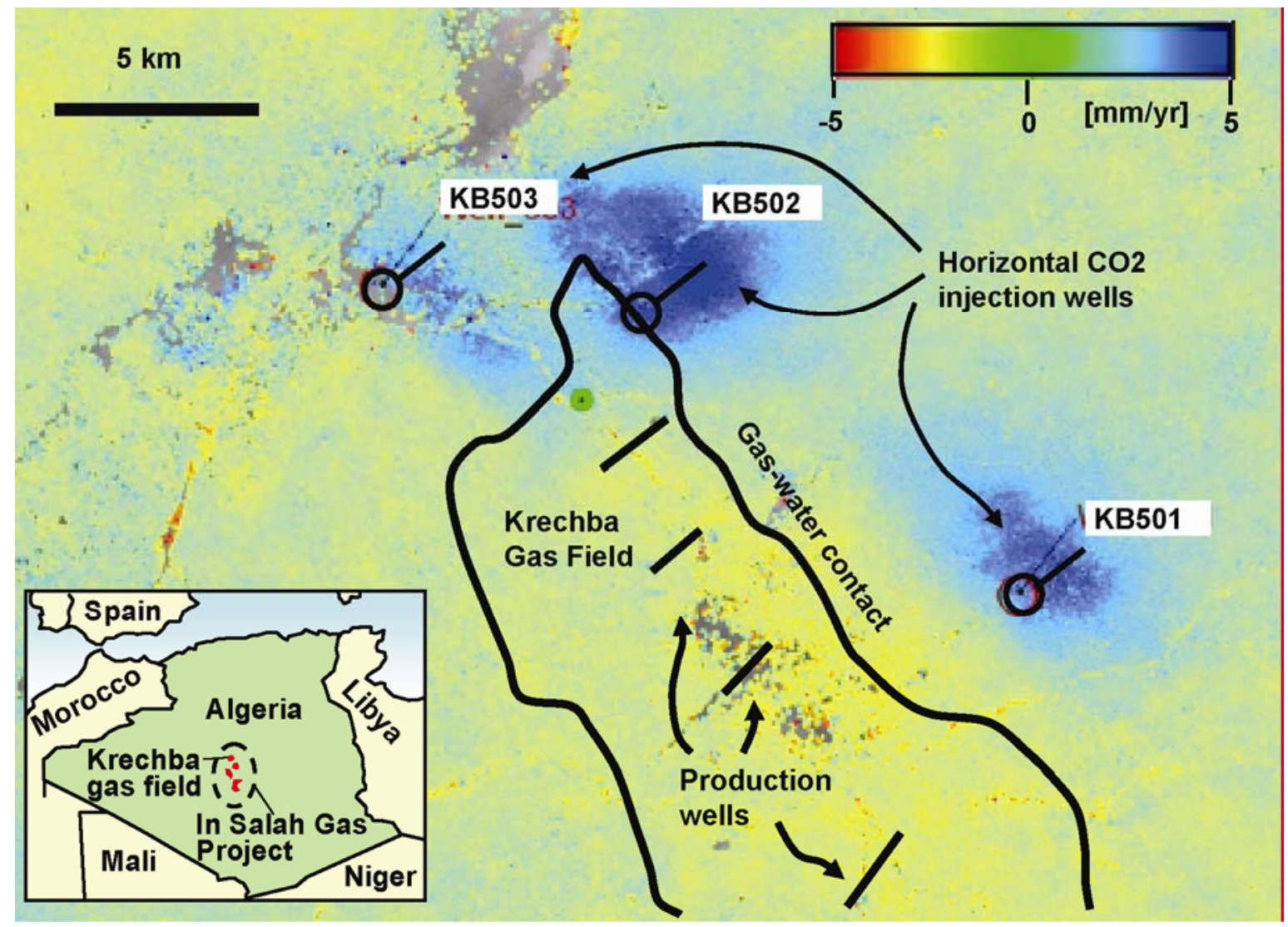

Figure 4. InSAR data of rate of vertical displacements for first 3 years of $\mathrm{CO}_{2}$ injection at Krechba (Rutqvist et al., 2010b). 


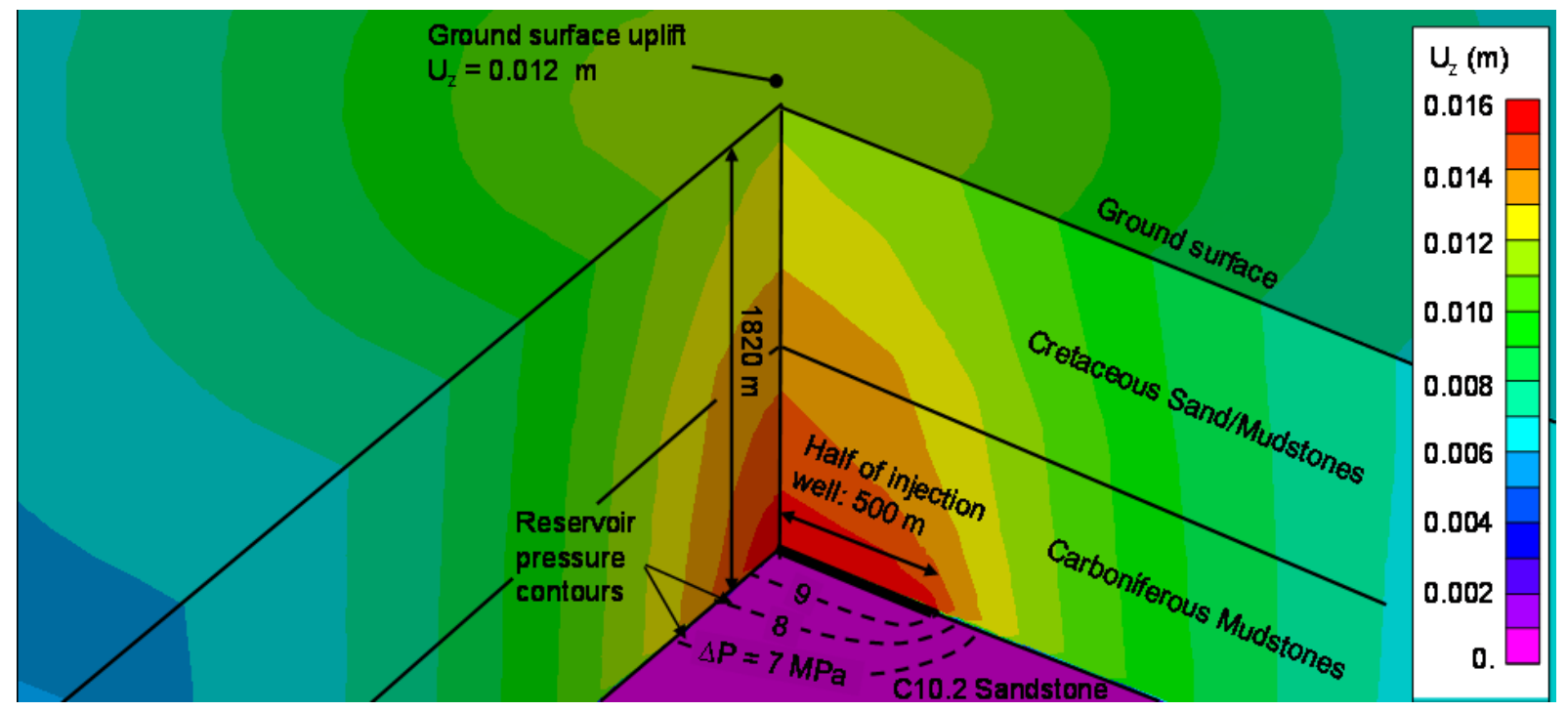

Figure 5. Simulated vertical displacement after 3 years of injection with a caprock permeability of $\mathrm{k}=1 \times 10^{-21} \mathrm{~m}^{2}$ (Rutqvist et al., 2010b). 


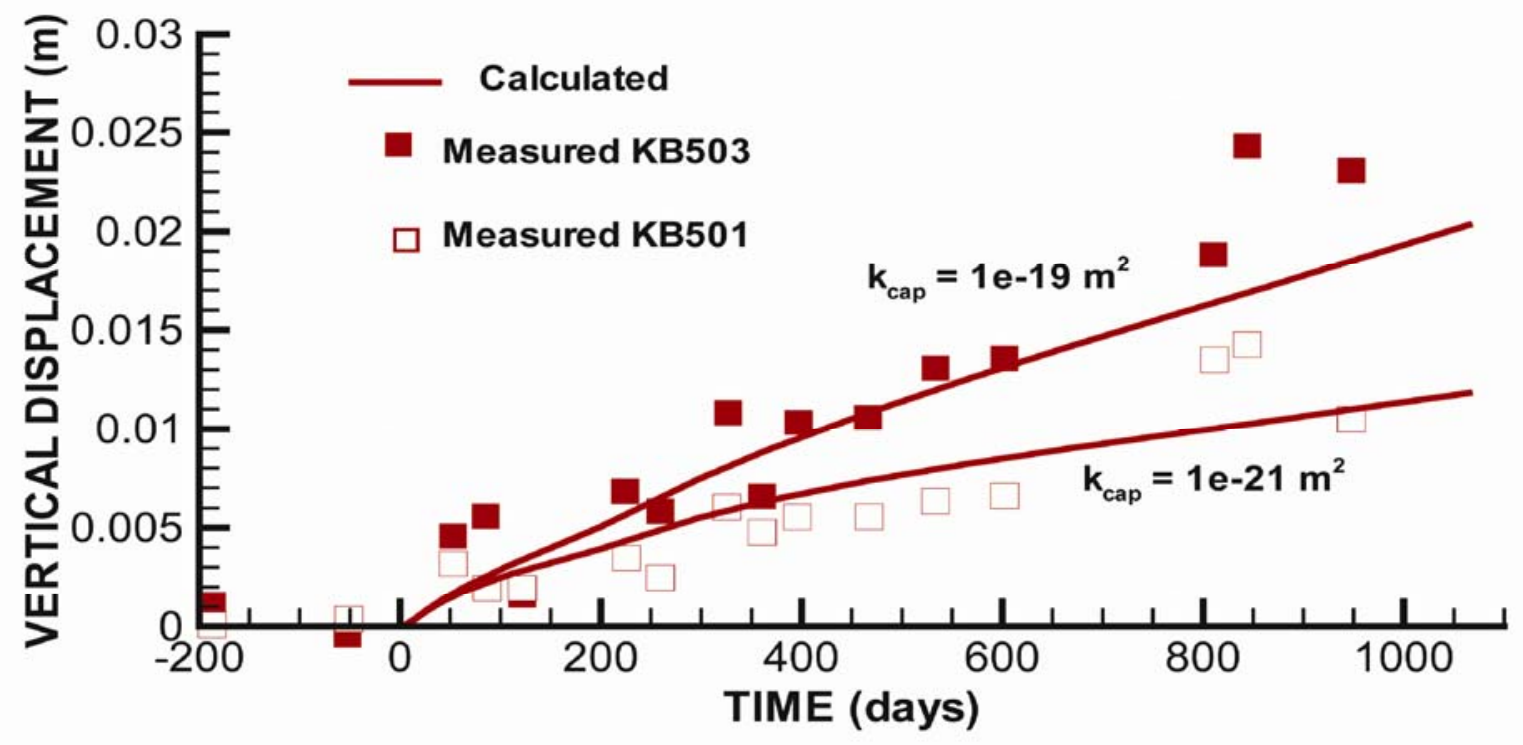

Figure 6. Comparison of simulated vertical ground uplift for two different values of caprock permeability (solid lines) to that of measured ground uplift above injection wells KB501 and KB503 (symbols). (Rutqvist et al., 2010b). 


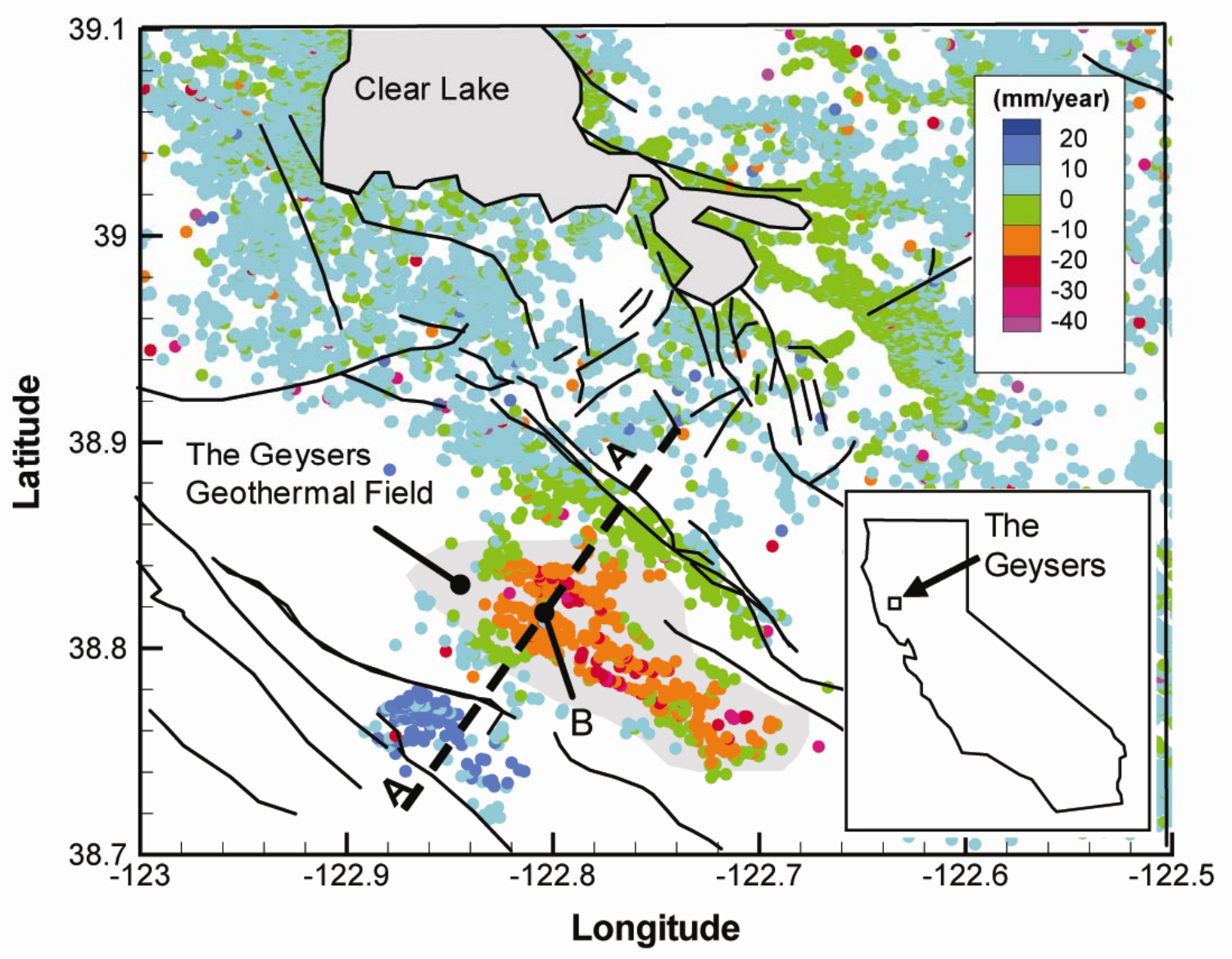

Figure 7. InSAR data of rate of vertical displacements at Geysers during 1992 to 1999. Data was acquired and processed by TRE on behalf of LBNL. 


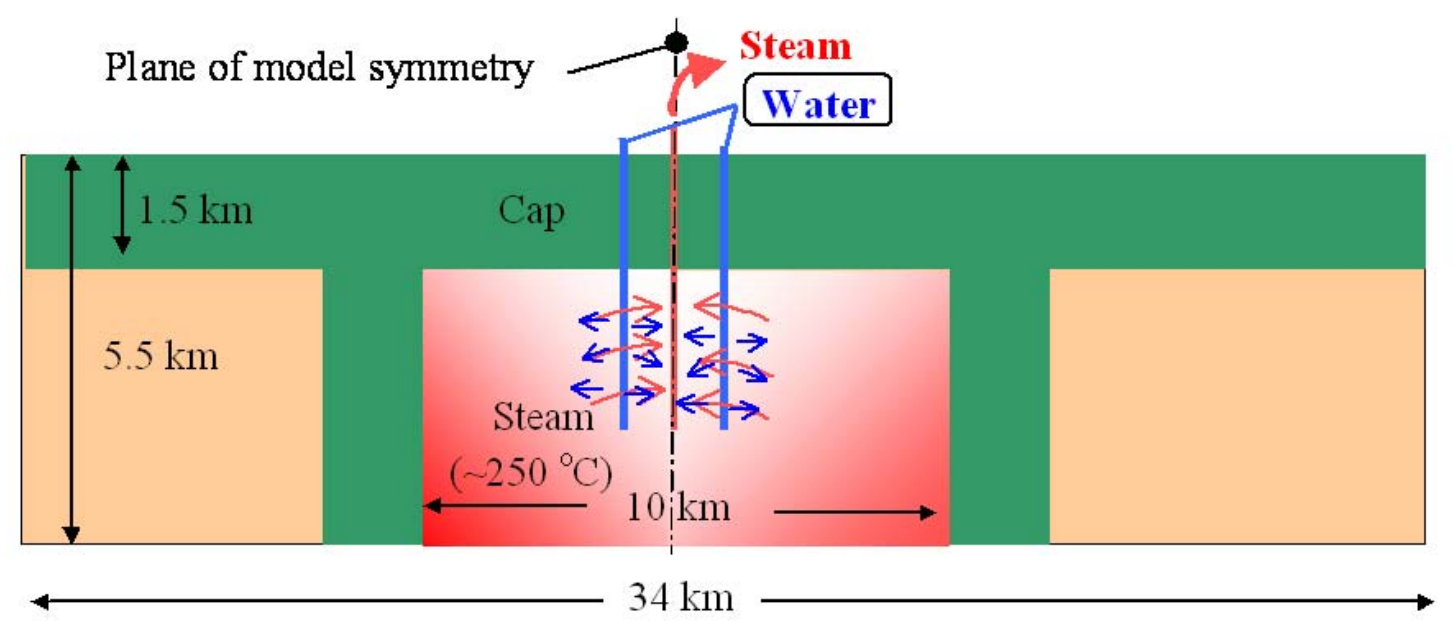

Figure 8. Model domain for a coupled geomechanical reservoir Geysers model aligned NESW across Geysers geothermal field along profile A-A in Figure 7 (Rutqvist and Oldenburg, 2008). Only one half of domain was simulated because of center plane of symmetry. Seam production rates and water injection rates for this model section was estimated from reservoir wide production and injection data (Rutqvist and Oldenburg, 2008). 


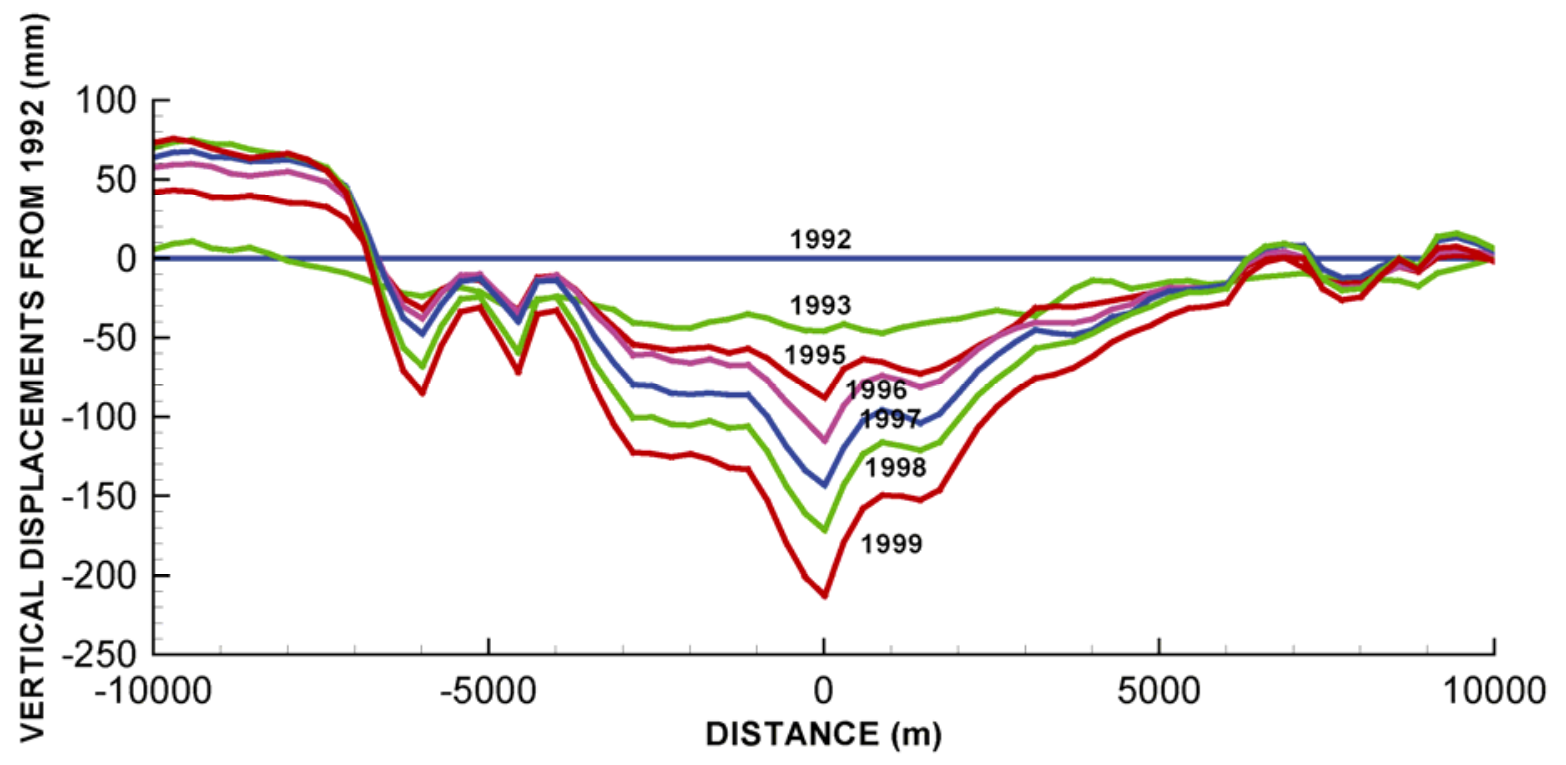

Figure 9. InSAR evaluated evolution of vertical surface displacement from 1992 to 1999 in along profile A-A in Figure 7. 


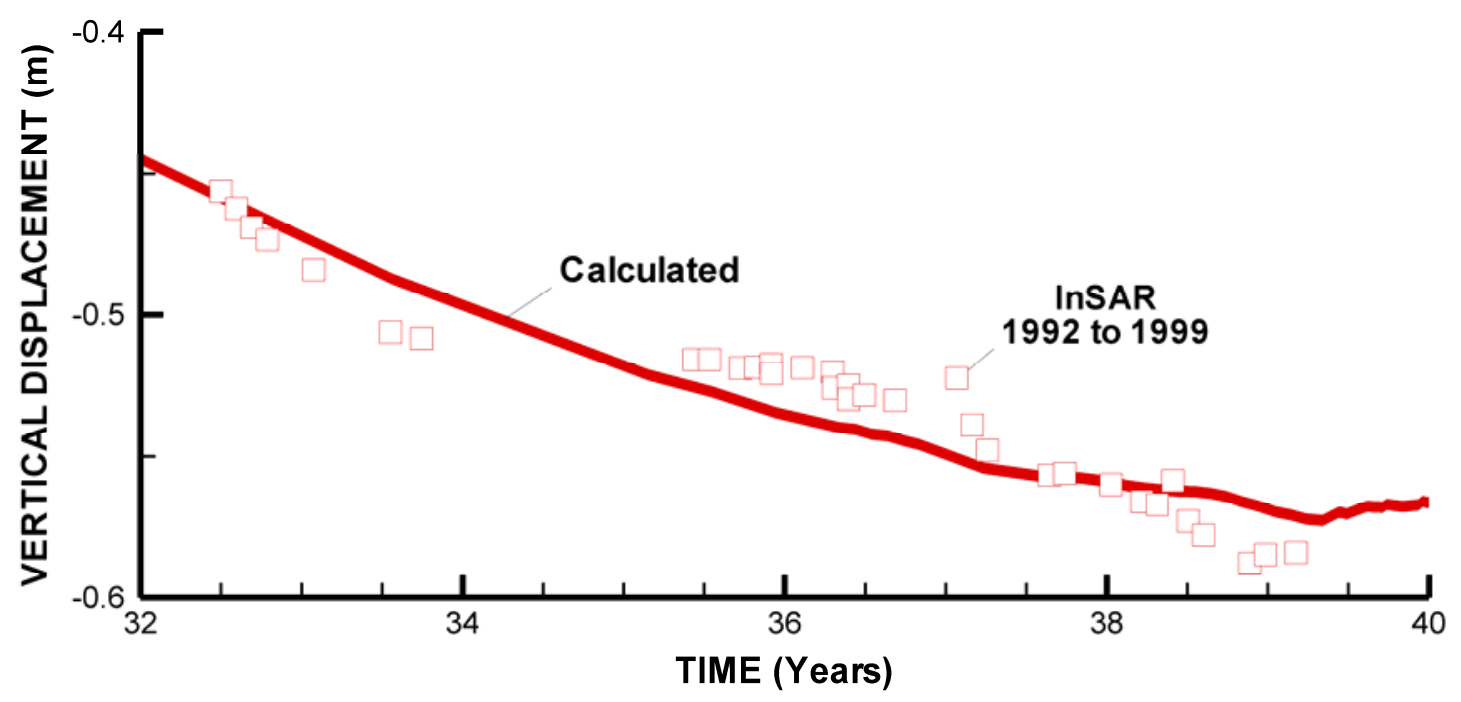

(a)

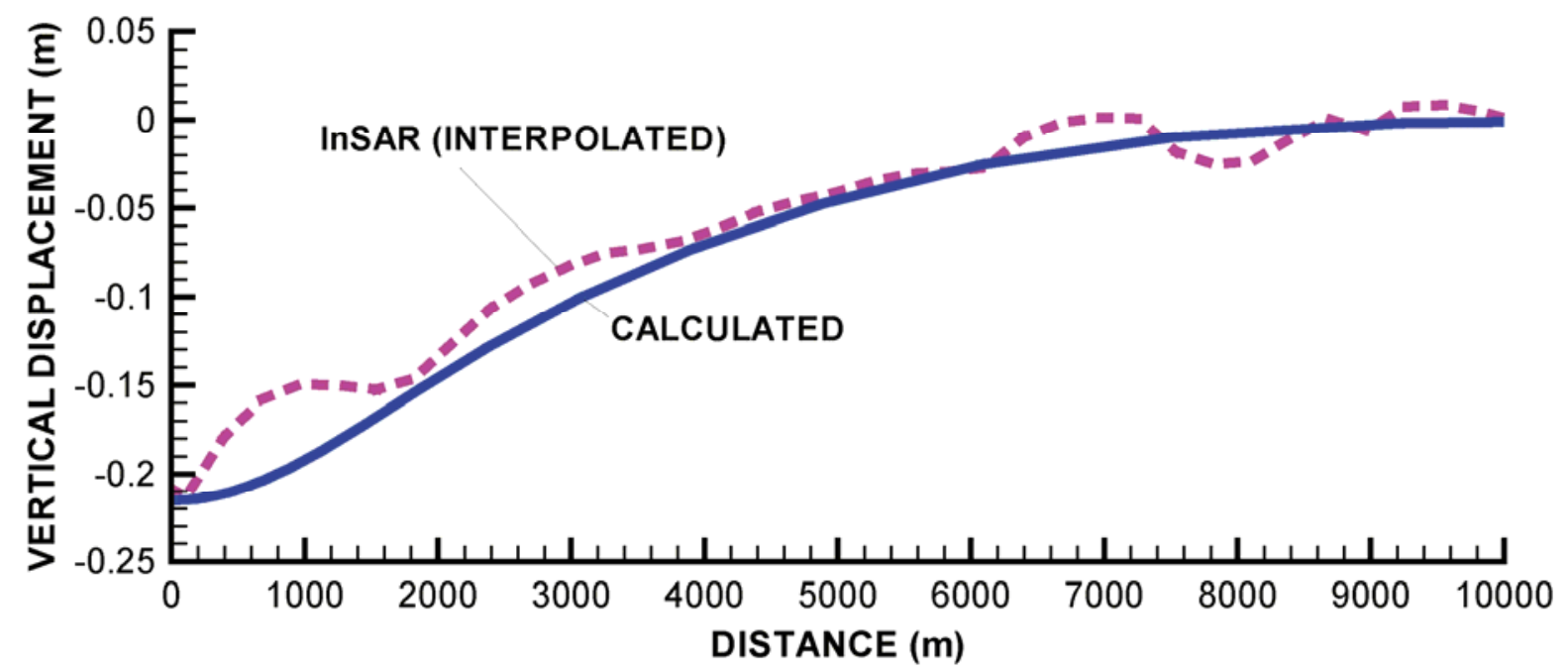

(b)

Figure 10. Comparison of calculated and InSAR evaluated vertical displacements from year 32 to 40 (1992 to 1999) since start of steam production at Geysers: (a) transient evolution at point B in Figure 7, and (b) total subsidence from 1992 to 1999 along profile A-A. 


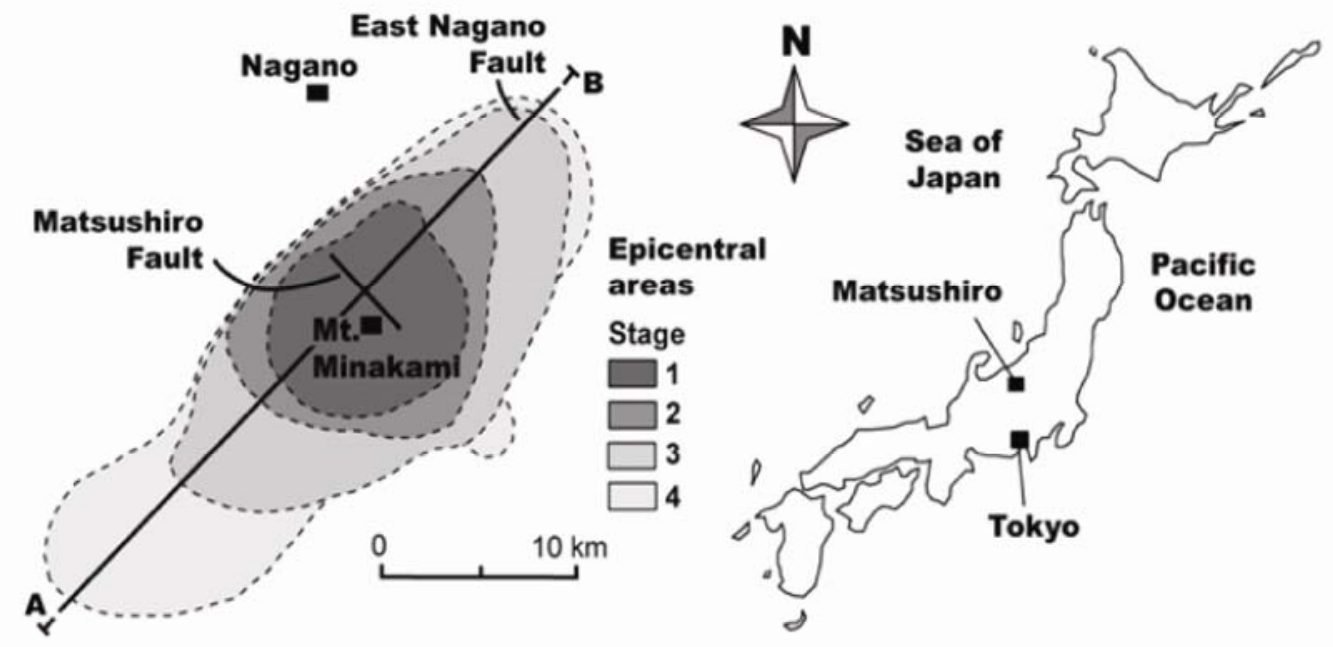

(a)

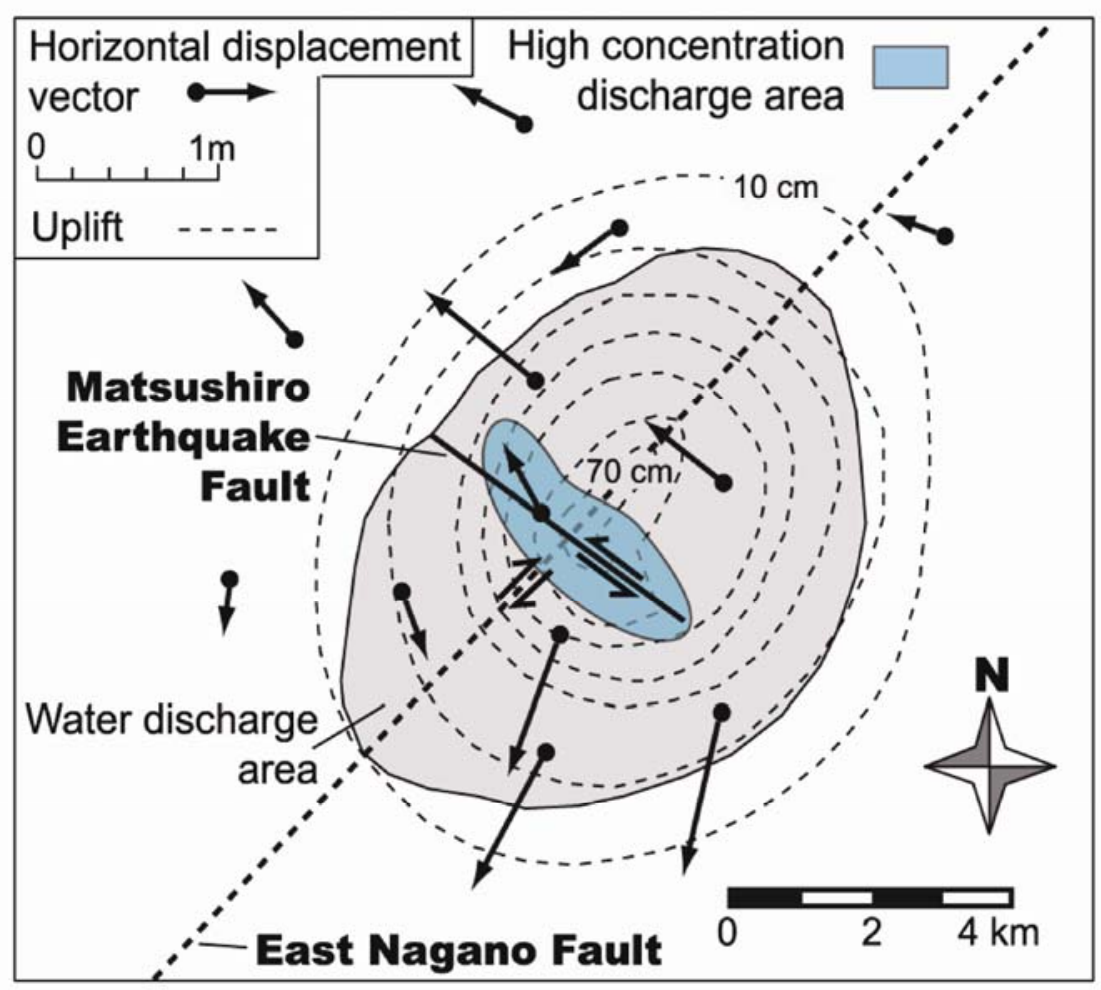

(b)

Figure 11. Observed crustal fluid flow and geomechanical responses during 1960s Matsushiro earthquake swarm: (a) Tectonic features and time series of epicentral areas, and (b) areas of maximum uplift, horizontal displacements and water discharge induced in September 1966 (Cappa et al., 2009; Othake, 1976). 


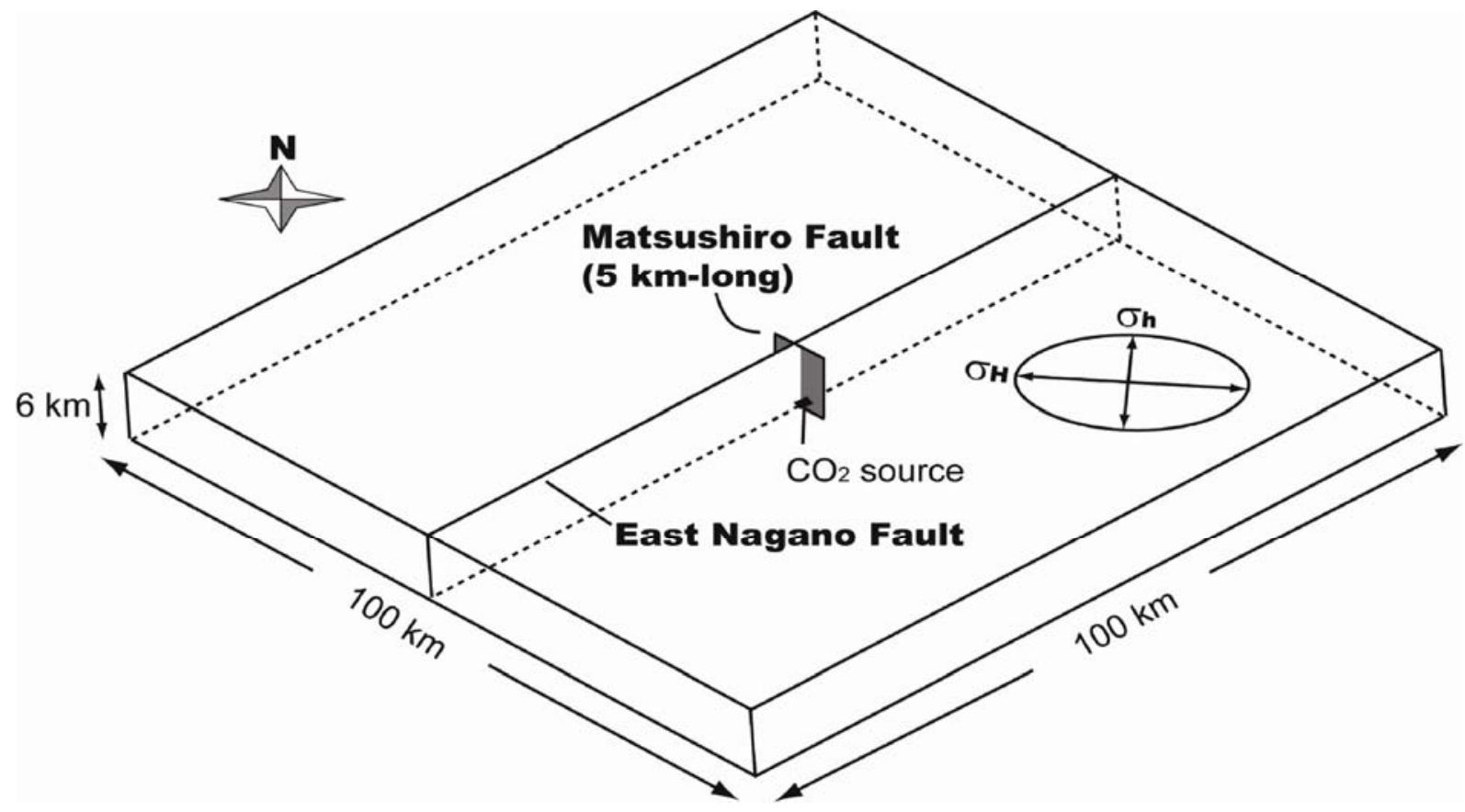

Figure 12. Model geometry including Matsushiro and East Nagano earthquake faults and orientation of strike-slip stress field (Cappa et al., 2009). 


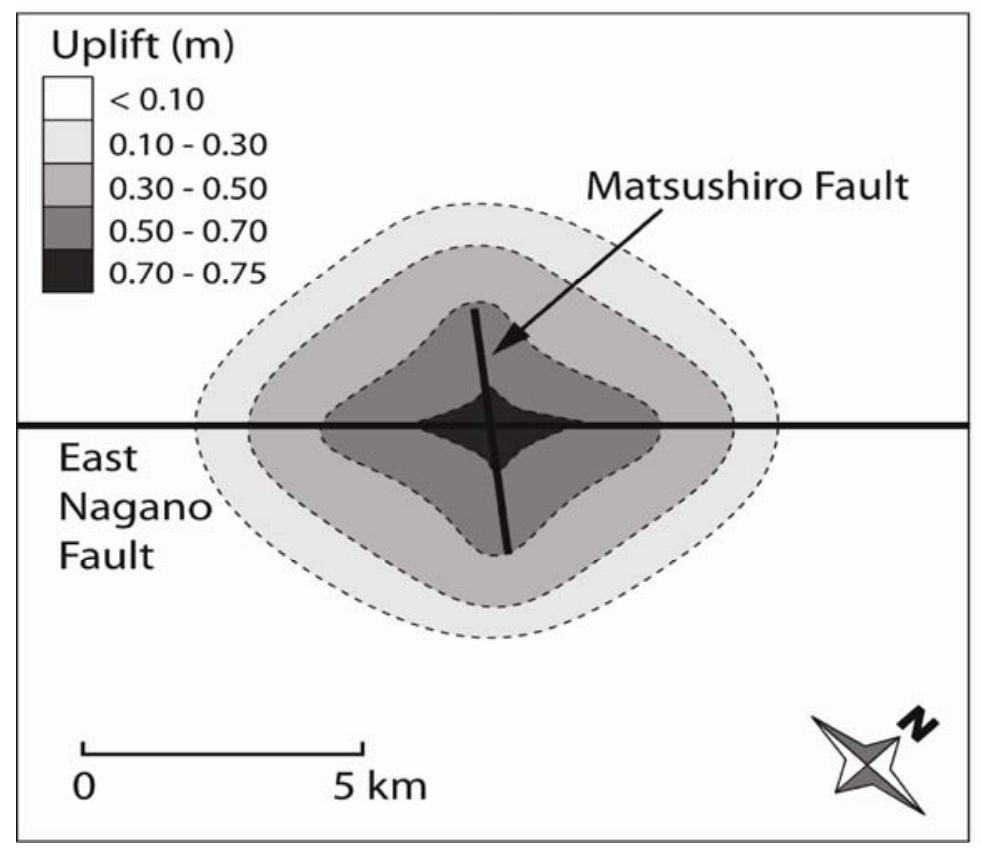

(a)

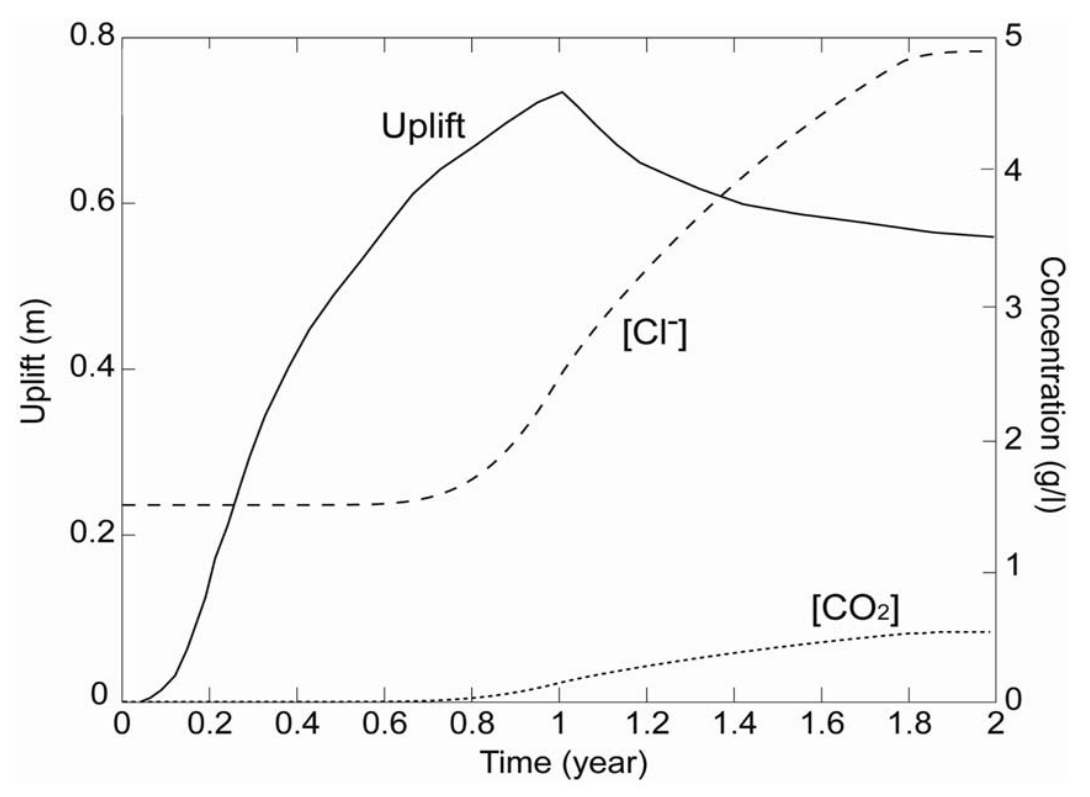

(b)

Figure 13. Calculated uplift and [Cl-] and $\left[\mathrm{CO}_{2}\right]$ concentration at ground surface (at intersection between Matsushiro and East Nagano faults (Cappa et al., 2009): (a) plane view of uplift at 1 year, (b) transient geochemical and geomechanical response at ground surface. 


\section{DISCLAIMER}

This document was prepared as an account of work sponsored by the United States Government. While this document is believed to contain correct information, neither the United States Government nor any agency thereof, nor The Regents of the University of California, nor any of their employees, makes any warranty, express or implied, or assumes any legal responsibility for the accuracy, completeness, or usefulness of any information, apparatus, product, or process disclosed, or represents that its use would not infringe privately owned rights. Reference herein to any specific commercial product, process, or service by its trade name, trademark, manufacturer, or otherwise, does not necessarily constitute or imply its endorsement, recommendation, or favoring by the United States Government or any agency thereof, or The Regents of the University of California. The views and opinions of authors expressed herein do not necessarily state or reflect those of the United States Government or any agency thereof or The Regents of the University of California.

Ernest Orlando Lawrence Berkeley National Laboratory is an equal opportunity employer. 